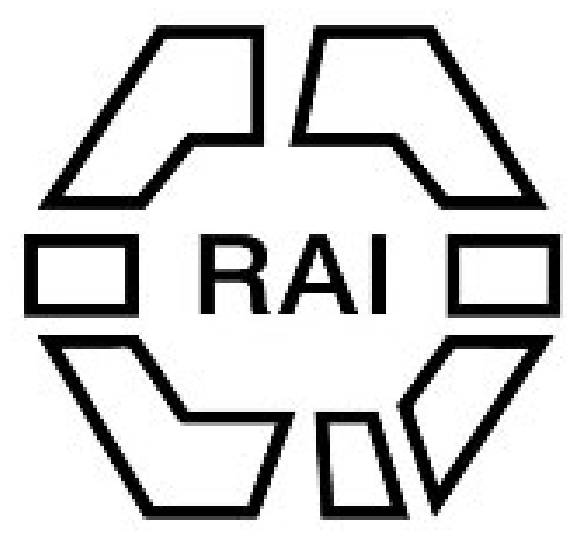

The Experimental Investigation of Flint Fracture and its Application to Problems of Human Implements.

Author(s): S. Hazzledine Warren

Source: The Journal of the Royal Anthropological Institute of Great Britain and Ireland, Vol. 44 (Jul. - Dec., 1914), pp. 412-450

Published by: Royal Anthropological Institute of Great Britain and Ireland

Stable URL: http://www.jstor.org/stable/2843364

Accessed: $10 / 04 / 2014$ 18:47

Your use of the JSTOR archive indicates your acceptance of the Terms \& Conditions of Use, available at http://www.jstor.org/page/info/about/policies/terms.jsp

JSTOR is a not-for-profit service that helps scholars, researchers, and students discover, use, and build upon a wide range of content in a trusted digital archive. We use information technology and tools to increase productivity and facilitate new forms of scholarship. For more information about JSTOR, please contact support@jstor.org. 


\title{
THE EXPERIMENTAL INVESTIGATION OF FLINT FRACTURE AND ITS APPLICATION TO PROBLEMS OF HUMAN IMPLEMENTS.
}

\author{
By S. Hazzledine Warren, F.G.S.
}

[With Plates XXXVIII-XL].

\section{Contents.}

\section{Part I.}

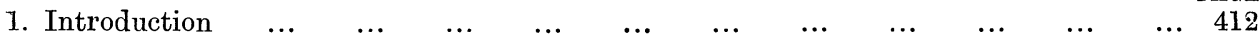

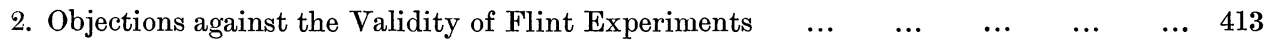

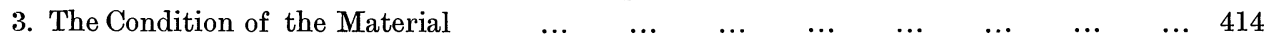

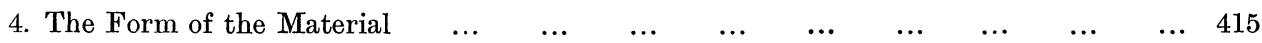

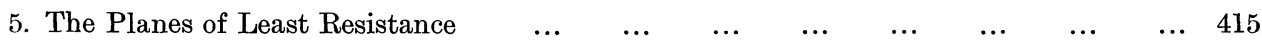

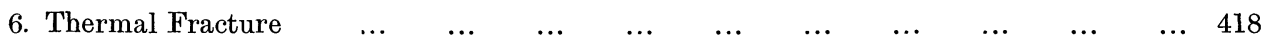

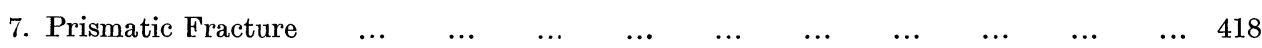

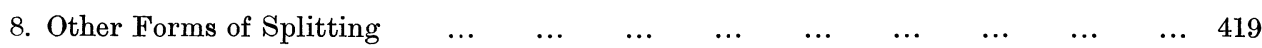

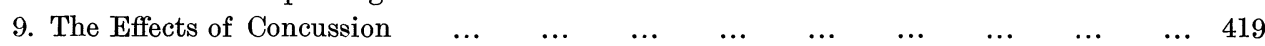

10. The Effects of Crushing and of Differential Movement under Pressure ... $\quad \ldots \quad \ldots \quad \ldots 23$

11. Application of the Study of Flint Fracture to the Problem of the Eoliths $\quad \ldots \quad$.. 427

12. The Harefield Section with Flint Chipping by Sub-soil Pressure $\quad \ldots \quad \ldots \quad \ldots \quad 431$

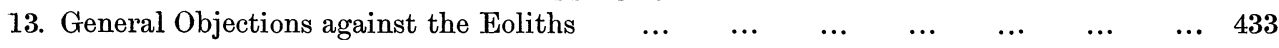

Part II.

14. Technical Details and Tabulation of Experimental Results $\quad \ldots \quad \ldots \quad \ldots \quad \ldots \quad \ldots 434$

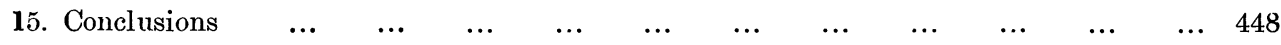
$\begin{array}{llllllllllllll}\text { Description of the Plates } & \ldots & \ldots & \ldots & \ldots & \ldots & \ldots & \ldots & \ldots & \ldots & 449\end{array}$

\section{PART I.}

\section{Introduction.}

THE: subject of the present communication is one which has not yet advanced beyond the stage of controversy. It is unfortunate that those who are the most entitled to judge in this matter are at considerable divergence among themselves with regard to conclusions which are of far-reaching importance.

It appears to me that an investigation of the elementary principles which underlie all flint chipping is no less important for the solution of the problems that are before us, than is the investigation of the structure of organized beings to the 
solution of the problems of palæontology. This view is by no means universally held. But even although we may not yet have succeeded in unravelling the essential from the tangle of the accidental, and many present mistakes may have to. be corrected, I believe that this method will ultimately be recognized as the only one compatible with the broader philosophy of science.

\section{ObJections against the Validity of Flint Experiments.}

If we knew nothing of the matter, and were shown a perfect crystal of a diamond and a rough piece of broken brick, I think we should imagine that there was more evidence of human design in the crystal with its perfect regularity of form and its polished facets, than there was in the brick. Where problems of human implements are concerned let us take warning lest we mistake the diamond for the brick.

I think it must be admitted that it is not satisfactory to base our judgment upon some vague intuition of that which we suppose should, or should not, constitute a genuine flint implement. And yet there are many workers who feel much inclination to discredit flint experiments. In my opinion this mistrust in flint experiments has arisen because these experiments have been approached from a mistaken point of view.

Experiment should hold a similar position in these problems to that which it holds in physics or in chemistry. It has been objected against the validity of flint experiments that the means employed to obtain an application of force are artificial and do not exist in Nature. Yet one has never heard a similar objection against the discoveries of physics or chemistry, on account of the apparatus and machinery which alone make those discoveries possible.

I think the explanation lies in the fact that in the problem before us there has not always been sufficient clearness of thought in distinguishing the experiment from its application.

It has been assumed, when a certain experiment has failed to produce a given result, that Nature is equally unable to produce that result when bringing into play her varied and powerful agencies. This is as unsound as it would be to assume that the result of a certain experiment must also be reproduced by natural agencies, without evidence that similar conditions exist in Nature to those. employed in the experiment.

As I have pointed out before, there are two most important factors which prohibit the experimental reproduction of natural conditions: namely, (1) the quantity of material operated upon, and (2) the time during which the forces of Nature are acting upon it. Experiment can neither reproduce natural conditions, nor can it directly show the product of those conditions. ${ }^{1}$

${ }^{1}$ I have elsewhere criticized the experimental methods of Mr. J. Reid Moir, see Man, 1913, 20 ; Geol. Mag., 1914, p. 546. 
The first purpose of flint experiments is the investigation of the physical properties of flint and its behaviour when subjected to various stresses. The second purpose is educative; to train the eye of the student in the recognition of the characteristics of the chipping produced by different methods. It is by experiment only that such knowledge can be gained; while without such knowledge there can be no scientific understanding of flint fracture.

Although experiments are not in themselves a reproduction of natural conditions, a little consideration will show that each class of experiment has its own value. For instance, the effects of cart-wheel crushing upon new roads have the merit of being absolutely fortuitous: there is no selection in the raw material used; neither are the flints placed in chosen positions when the force is applied.

At the same time, this indefiniteness, and the uncertainty in the force which may have come into play, have their own disadvantages. In order to understand this simple operation of cart-wheel crushing, it is necessary to experiment with flints of chosen shape, and to place them in definite positions against other stones when the force is applied, in order to discover how the edge-chipping takes place, and why it occurs in some instances and not in others.

\section{The Condition of the Material.}

If a flint be dropped upon a hard surface, it may instantly fly into a large number of angular fragments. This is a flint which has become intersected, throughout its mass, by incipient fractures. These flaws are most commonly the result of the molecular strains set up by rapid changes of temperature (thermal fracture). If this process has proceeded far, it is not possible either to flake the material by hand, or chip it by any process of concussion or pressure, except along the lines of its own incipient shattering.

If another flint be subjected to a similar force, it may be found that although the process be repeated many times, no result is obtained beyond a slight bruising or contusion of the surface. This is because the flint has become toughened or annealed, and, to a considerable degree, resistant to fractures of any kind.

If a third flint be tried, it may be found that on the first or second trial a neat "bulbous" chip will be detached, leaving a concave facet behind it upon the stone. This is a flint in that which I propose to describe as a "flakable" condition.

The best flint for flaking purposes is that which has been freshly taken out of the chalk. Fresh flint, however, varies in flakable quality; that obtained from certain beds in certain districts being superior to the average.

Flint in perfectly flakable condition may, however, be found abundantly in many of the Pleistocene gravels, and other superficial drift deposits.

The variation in the flakable quality of different flints introduces great complications into the results of all experimental flint chipping. In the experiments 
which I am about to describe, a considerable variety of raw material has been used, but, unless expressly stated to the contrary, it is always drift flint. This has been collected from a considerable area of country over Hampshįre, Kent, Middlesex, Hertfordshire, Essex, Lincolnshire, and elsewhere. The general results do not refer to the flint of any one locality, which may be especially favoured or otherwise.

\section{The Form of the Material.}

Not less important than the quality of the raw material to be used in flint experiments, is the consideration of its form. Throughout all flint experiments, it is no less true with respect to form than it is with respect to condition, that an effect which is inevitable upon one piece of flint is unobtainable upon another, either by the same or by any other mechanical process.

As it is not possible for the experimenter to work upon the raw material in bulk-indeed it would only lead to confusion if he did-it is essential for him to select his raw material into groups according to form, such as, cylindrical, pseudospherical, tabular, plano-convex, and the like. If we wish to know the effect of a mechanical force upon a flint, it will lead to false results if we take one belonging to a different group as our guide.

Although flint is always uncertain, the results obtained upon each group tend to follow certain definite lines, which, broadly speaking, can be clearly laid down.

It will thus be understood that it is of little value to give the proportion of successes to failures obtained in any process, as this proportion depends upon the selection of the raw material which may be used.

In obtaining raw material for flint experiments, it is possible to select, at will, that which will give 100 per cent. of failures, or that which will give between 50 and 100 per cent. of successes.

If I may anticipate a point in the application of experimental results to natural conditions, Nature does not select out the "suitable" raw material and preserve it from coming under the operation of her agencies, but all classes are subjected to the same forces, and that which is "suitable" alone receives its appropriate chipping.

\section{The Planes of Least Resistance.}

In attempting to reproduce imitations of prehistoric flint implements, the first thing that is discovered is that flint fractures along certain planes of least resistance. Along these planes, good flakes may be struck off with facility, while in other directions the flint may be battered repeatedly, and by more forceful blows, without any success in the removal of a flake.

These planes of least resistance sometimes tend to run parallel to the original cortex of the nodule, but they are greatly modified by irregularities in the toughness of different parts of the same stone. In the case of flint that has been broken up by thermal, or other strains, the direction of the planes of least resistance to fracture is 
largely determined by the angles and curvatures of the external faces of the fragments; and also by the practicability of obtaining an adequate "grip" upon the surface for the reception of the blow.

If the angle of an edge be greater than a right angle, the force required to remove a flake of a given size is also greater (other things being equal) than when the angle is less than a right angle. There is also, under the former conditions, a tendency to produce a mere contusion of the surface rather than to remove a flake.

If the angle of an edge be a low angle of less than $45^{\circ}$, there is a tendency for the angle of the flake removed to be also low, and for the flaking to run far back over the face of the stone. It is this tendeucy which comes to be instinctively encouraged by man in the flaking of flint implements, other than flake implements or the bevelled edge of scrapers. It is the conscious adaptation of this principle to the production of some useful form of implement that is the distinguishing feature of human workmanship.

The original angle of the edge from which flakes are removed will be referred to as the flaking angle where human work is concerned, and the chipping angle where the work is of mechanical or doubtful origin.

In former papers I referred to all flint chipping as " Hlaking." For the sake of additional clearness, I propose to confine the use of the term "flaking" to the human technique. The process of removal of thin plates from the surface of flints by thermal fracture, may appropriately be defined as "scaling" rather than " flaking."

The flaking (or chipping) angles are illustrated in the diagram (Fig. 1), where the plane $\mathrm{A} \mathrm{B}$ is the striking plane. The angle $\mathrm{A} \mathrm{B} \mathrm{C} \mathrm{is} \mathrm{the} \mathrm{outer} \mathrm{flaking} \mathrm{angle.}$

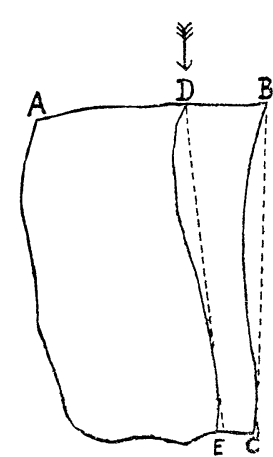

FIG. 1.-DIAGRAM SHOWING THE FLAKING ANGLES. After the removal of a flake along the plane $\mathrm{D} \mathrm{E}$, by a blow delivered in the direction of the arrow at the point $\mathrm{D}$, the angle A D E becomes the inner flaking angle, and B D E the re-entrant flaking angle. It will be understood that these flaking planes of conchoidal fracture are nearly always undulating, in consequence of which mathematical accuracy in the measurement of the angles is unattainable. I have taken the nearest straight line to the most important part of the curve, as shown by the dotted lines. In the case of greater irregularities of surface the specimen has to be eliminated as unsuitable for measurement.

In further definition, a flake struck in the manner indicated by the arrow may be described as "plane-struck," that is removed by a blow struck well on the striking plane. If the flake be removed by a blow delivered close to the point B, it may be described as "edge-struck."

The natural laws of the facility of chipping along the planes of least resistance, of the possibility of the control of the material in designed flaking, and of the limitations of that possibility, are those which are at the foundation of all flint chipping. 
The diagram (Fig. 2) illustrates in cross-section the removal of three successive flakes, in the order in which they are numbered $(1,2,3)$, firstly (A) along the planes of least resistance, which results in the blunting of an original sharper edge, and secondly (B) the most elementary form of the control of the material in the production of a sharp edge.

The planes of least resistance to fracture observed in the flaking of implements, are also found to hold in the case of experimental chipping by mechanical force.

An illustration of this is shown sectionally in the diagram (Fig. 3). The specimen from which this diagram was taken measured $81 \times 62 \mathrm{~mm}$. across the basal plane, and was $39 \mathrm{~mm}$. in thickness. Blows of an energy of $1 \cdot 1$ watts $^{1}$ delivered upon the basal plane from

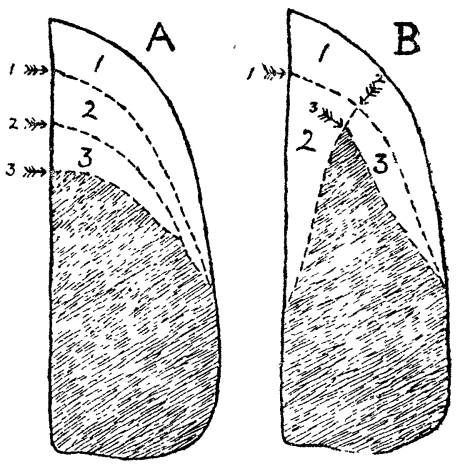

FIG. 2.- SECTIONAL DIAGRAM SHOWING (A) CHIPPING ALONG THE PLANES OF LEAST RESISTANCE, AND (B) ELEMENTARY CONTROL. the directions $a, a^{\prime}, a^{\prime \prime}$, produced free chipping on the edges. In the case of blows delivered from this general direction $a$, there is a wide range of angle at which they may fall without producing much modification in the results. From the direction $\beta$, blows of about the same force may remove chips nearly parallel with the basal plane, but there seems to be a narrower range of angle from which the blows may be delivered, and there is a practical difficulty in obtaining an effective application of force in this edgewise position. The flint to be operated upon will naturally rest upon either side, but not so steadily upon its edge.

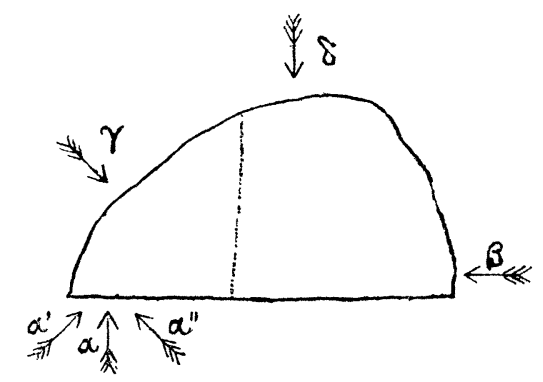

FIG. 3.-DIAGRAM OF RESISTANCE TO FORCE IN DIFFERENT DIRECTIONS iN A FLINT OF PLANO-CONVEX FORM.

In the direction $\gamma$, the force of the blows was raised to an energy of 4.65 watts before a chip was removed. In the $\delta$ direction, the impact of the blows was gradually raised to 29.4 watts, but the only result (an extremely important one however) was further edge-chipping in the $\boldsymbol{a}$ direction by the back-pressure of the stones on which it rested. The support used was damp gravel of fine grade. The impacts could not effectively be further increased without the use of a more resistant support.

It will be understood that it is not possible to give a ratio for $a$ and $\delta$ chipping, which would be universally true; it depends 'entirely upon the form and condition of the flint used. But the experiment described above illustrates a general principle which is of wide application.

It is only in the event of the $a$ chipping becoming cut far back into the body

1 For an explanation of these technical points, see Part II:

VOI. XLIV. 
of the stone, as suggested by the dotted line in Fig. 3, that chipping in the $\delta$ direction becomes obtainable with reasonable facility upon a flint of the form indicated.

I submit that this tendency of flint chipping is little less than a law of vital importance to the elucidation of the problems before us. Under certain welldefined conditions governed by the form and quality of the flint operated upon, we find: That forces acting from a wide range of angle upon either side of a flint tend to produce chipping in one direction only, rather than in the various directions corresponding to the incidence of the blows.

Such selective chipping in one direction, which is in reality the natural result of forces acting mechanically from all directions, not infrequently simulates the operation of intelligent design.

\section{Thermal Fracture.}

This is generally taken to refer, not to the calcination caused by burning, but to a special form of fracture due to rapid changes of temperature, associated with frost, sun-heat, and the like. By such means strain is set up within the mass of a flint through unequal expansion or contraction. Starting from an internal point, the strain passes outwards on every side towards the periphery of the object in a series of ripplings, until the nodule parts along the plane of separation thus produced.

This fracture, in its ideal development, may be recognized by the surface ripplings, which are approximately concentric to some point on the interior of the fractured surface, but not always in its centre. This point is not infrequently associated with some fragment of fossil embedded in the stone, or of some other inequality in its texture (Plate XXIX, Fig. 8). This is one of the easiest forms of fracture to recognize, and is seldom mistaken for anything else even by the least experienced.

Thermal fracture also acts in a more superficial manner in the removal of shallow pits, known to the French as "pock-marks." These are extensively developed upon the surfaces of flints exposed to sun-heat on the Egyptian desert.

\section{Prismatic Fracture.}

This is a form of fracture in which the flint is split up into prismatic splinters. The surface ripplings are poorly developed and peculiar: when present they often radiate both longitudinally and transversely. This fracture may, I think, usually be traced to the shattering of the flint nodules by tectonic movement in place in their original position in the chalk. I have frequently observed it in such situations. It may, however, be produced by any other violent shattering of the material ; as illustrated, for instance, under Section 12 of this paper. 
There is nothing in this fracture which should cause it to be mistaken for human work, although, as a matter of fact, during the past two or three years examples have been purchased as human implements (which did not claim to be pre-Palæolithic) by one of our large museums, and other illustrations have been figured in a recent scientıfic mernoir of great importance.

\section{Other Forms of Splitting.}

One may place in this group the inosculating flaws associated with calcination, but this need not detain us here.

There is, however, one other point which should be noted, and this is fracture by indirect violence, or the breaking of flint by tension or flexion at some point other than that at which the force is applied. It is easily produced experimentally by striking the branch of a flint nodule, when it may part, not at the point of impact of the blow, but across the neck connecting the branch with the main part of the nodule.

The fractured surfaces have no cone of percussion, and frequently tend to be remarkably flat. I believe that these fractures take place beneath the surface, in flints embedded in drift, through subsoil movements.

These breakages cannot in themselves be confused with human flaking, but they have a direct bearing upon our inquiry, because they frequently present favourable angles from which further chips may be removed by other means.

In fractures caused by flexion there is frequently a hinge-like curve developed at the axis of the bend, as illustrated in the diagram (Fig. 4), where the end B is being violently bent away from the piece $A$. This form of hinge-fracture is familiar from its occurrence in prehistoric axe- and adze-blades of flint which were broken in manufacture or by violent usage, apparently of a kind which brought a lateral strain into play. It cannot be adapted to any useful purpose for the making of implements, but

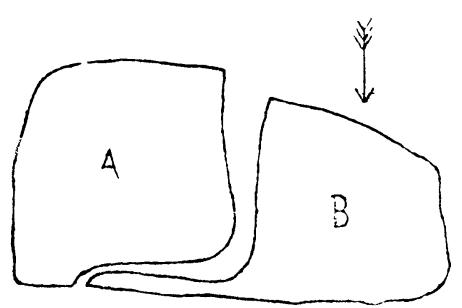

FIG. 4.-DIAGRAM SHOWING HINGEFRACTURE BY A FORCE INDUCING FLEXION, is a constant source of damage.

\section{The Effects of Concussion.}

Fractures by concussion, or the shock of one stone striking against another, may take place by various means where neither stone is held in the hand.

When a branched flint nodule is subjected to a series of concussions caused by other stones striking against it, the branches are first detached across the narrower necks which connect them together. We have now two, three, or more angular 
flints in place of one whole nodule. This is illustrated in the generalized diagram (Fig. 5), where the original nodule is broken into four pieces $\mathrm{A}, \mathrm{B}, \mathrm{C}$, and $\mathrm{D}$.

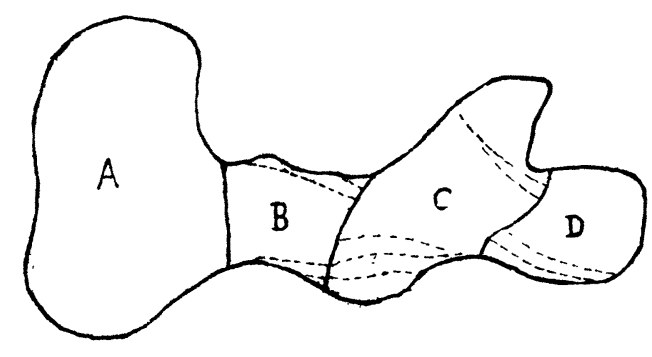

FIG. 5.-DIAGRAM SHOWING THE FIRST STAGES IN THE BREAKING-UP OF A BRANCHED FLINT NODULE, WITH THE PLANES OF LEAST RESISTANCE IN THE SEPARATED FRAGMENTS.

Examination of these four pieces will show that the angles made by the newly fractured surfaces with the cortex of the nodule, now give certain planes of least resistance to fracture. These are shown in the diagram by the dotted lines; the fragment $A$ having none.

If such pieces as $\mathrm{B}, \mathrm{C}$, or $\mathrm{D}$ be subjected to further concussions of moderate violence, it will be found that a series of parallel chips may be detached along the planes of least resistance upon the principle already explained.

In the operation of mechanical concussions, such large and complicated issues are involved that it is not possible to deal with them adequately within reasonable limits of space. I will describe some characteristic examples, and must leave the reader to fill in much for himself.

The specimen illustrated in Plate XXXVIII, Fig. 1, was placed in a slight hollow in the ground, and was subjected to the impact of pebbles weighing $0 \cdot 178$ kilogrammes ( $6 \frac{1}{4}$ ounces) falling under the acceleration of gravity from a height of 1.06 metres ( $3 \frac{1}{2}$ feet), giving a kinetic energy of 2.0 watts. This force gave free $a$ chipping from the basal plane at the smaller end of the flint, but not at the thicker end, owing to the greater resistance that it offered.

In the three views given of this specimen $(1 a, 1 b, 1 c)$ the crosses indicate ineffectual impacts, and the dotted outline round $1 b$ shows the chips removed.

It is instructive to note that some of the blows upon the basal plane fell near the point of the flint, but the point was not broken away owing to the strength of the ridge that was behind it. The original shape of the flint having a slight lateral curve, the specimen assumed the "rostro-carinate" form. As it chanced, the blows in the $\beta$ direction glanced off without effect; if they had fallen in such a manner as to obtain an adequate "grip" upon the surface (which they might have done), $\beta$ chipping nearly parallel to the basal plane would have occurred. Even in that event, the result would have presented marked contrast with the most elementary form of control illustrated in Fig. 2, B. To obtain $\gamma$ or $\delta$ chipping would have required a greatly increased kinetic energy.

In general comment upon these examples, and also upon that previously described under the heading of "The Planes of Least Resistance," I would wish it to be clearly understood that these are not fortuitous results, but deliberate and carefully planned experiments conducted for the purpose of investigating the chipping properties of flints of definite natural form. 
In order to check these conclusions with regard to selective $a$ and $\beta$ chipping I have bowled the flint to be operated upon along a shingle beach. In this method the incidence of the impacts is fortuitous.

The results depend partly-as in all cases-upon the form of the raw material, and partly upon the strength of the force brought into play. If the force be sufficient to effect $\delta$ chipping, the influence of the selective $a$ chipping is largely lost. But if the force is more moderate, selective $a$ and $\beta$ chipping may be obtained. ${ }^{1}$

The specimen illustrated in Plate XXXIX, Figs. $1 a, 1 c$, was treated in this manner, and it shows three parallel $a$ chips along one side, the opposite side not presenting such a favourable angle for chipping.

One of these three chips is twinned. The diagram (Fig. 6) illustrates a twin facet springing from one point of impact. The surface ripplings take a double curve upon either side of a dividing line between them, and the one chip separates into two. This form of twinning may be observed in human flaking; I am not well assured of its value, but $I$ am under the impression that it is more commonly seen in non-human chipping than in human flaking. It is frequently to be observed in the effects of crushing.

The flint shown in Plate XXXIX, Figs. $2 a, 2 b$, was treated in the same manner as the last, but the process was carried further. Again we find chipping along the planes of

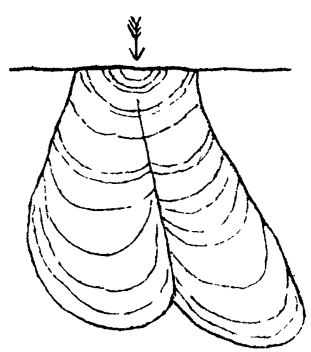

FIG. 6. -DIAGRAM OF A TWIN FACET. least resistance, and ineffectual contusions and incipient cones of percussion where the blows impinged against the flint in the more refractory directions. This example shows $a$ chipping in the upper view (2a) and $\beta$ chipping across the basal plane (2b).

These last experiments come into the group which I propose to call " Reverse Concussion," in contradistinction to "Direct Concussion." That is to say, the flint operated upon is itself the moving body striking against a stationary " anvil-stone" placed on the ground.

In dealing with material of plano-convex form, it is found that the conditions governing $a, \beta, \gamma$ and $\delta$ chipping, respectively, follow the same general laws that have been already explained, except that perhaps $\beta$ chipping is more easily obtainable, owing to the fact that the difficulty of placing the raw material steadily upon the ground in an edgewise position is not experienced.

A fortuitous incidence of blows may also be obtained by " reverse concussion," if the flint to be operated upon is held in the hand, in a different position each time, and thrown up into the air with a very slight rotary motion, so that the manner in which it strikes the "anvil-stones" is absolutely fortuitous.

${ }^{1}$ Selective $a$ chipping is also observed in the wash-mill effects, see M. Boule, L'Anthropologie, T. xvi, 1905, p. 257. 
The example illustrated in Plate XXXVIII, Figs. $2 a, 2 c$, was made by this process from a sub-cylindrical nodule, and it resulted in an astonishing simulation of a hand-axe, with an admirable hand-grasp and an excellent cutting-edge. From the purely utilitarian point of view, and neglecting the beauty of fine finish, it would be difficult to improve upon this as a primitive stone implement. The technical characters of the chipping were, however, purely eolithic (but not Kentish eolithic), and not palæolithic. The maximum kinetic energy brought into play was about 24 watts, but this method does not admit of an accurate calculation, as the height of fall can only be approximately measured.

The next example, Plate XXXVIII, Figs. $3 a, 3 b, 3 c$, was made from a flattish nodule, but not true "tabular" flint. It resulted in a form simulating a doubleended battle-axe, with two excellent cutting-edges, and a slight constriction round the middle for binding to the handle! The maximum kinetic energy brought into. play was $8 \cdot 5$ or $9 \cdot 0$ watts.

The chipping upon these two specimens is very suggestive of control. It is not confined to the $\boldsymbol{a}$ and $\beta$ planes of least resistance. The original form of the raw material did not lend itself to this selective chipping; and the force brought into play was sufficient to strike through in the oblique, or $\gamma$ direction. Practically the only guide to show that these are not implements made by hand-flaking is found in the technical characters of the chipping-characters which are extremely important, but by no means uniform or easy of recognition.

The case for the determination of hand-flaking from the effects of concussions is not, however, so difficult as might appear from the foregoing. Such results as the two that we are considering are very exceptional, and if the total results were before us instead of two picked specimens, there would be evidence apparent to the trained observer that these were an associated group due to the same cause, and that this cause was a purely mechanical force.

It is true that palæolithic implements are selected, as an associated group by themselves, from the river gravels in which they are found, and it may be argued that there is equal justification for selecting the eoliths. This leads us to the difficult question of deciding the difference between that which may safely be determined as different in kind, and that which is different only in degree, from the (admittedly) naturally broken stones among which it is found.

On general lines I would submit that the exceptional results obtained by the fortuitous concurrence of mechanical causes, should lead us to expect something of an analogous kind from the fortuitous concurrence of natural causes.. Beyond that, in questions of selective separation, or associative grouping, we are thrown upon the personal judgment of the trained observer, based upon an examination of the specimens themselves, just as we are in the determination of a shell or a bone.

The effects of "reverse chipping" are found in human workmanship. If, in using a hammer-stone of flint, a splinter flies backward off the hammer-stone instead of, or in addition to, that which it is intended to remove from the object struck, it 
will be found that the characters of the chip resemble those obtained in mechanical " reverse chipping."

In addition to this semi-accidental illustration, a true "reverse flaking" is occasionally found as a deliberate technique of workmanship. That is to say, the miplement in process of fabrication is struck against an anvil-stone instead of being struck by a hammer-stone. This technique tends to exhibit similar characters to mechanical reverse chipping, although they are not so pronounced.

There is one special technique of human flaking which presents certain peculiarities. In this method the facets are longitudinally convex, and the chips removed (viewed from the inner face) are longitudinally concave.

The purpose of this technique, which may be named "incurved flaking," is to reduce the thickness of the centre of the stone blade. This is illustrated in the sectional diagram (Fig. 7), where four flakes have been successively removed in the order in which they are numbered.

As a name for a definite style of work, found on certain palæolithic and neolithic working sites, the term "incurved flaking" should not be understood in a too restricted sense. It is a clearly defined group, representing a definite technique, which seems to be associated with the finishing of the larger implements; the incurved character being the dominant tendency, but it is by no means miversally present. This technique shows a high skill, and I have not been able to

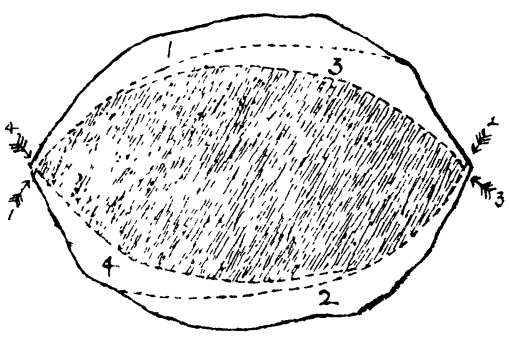

FIG. 7.-SECTIONAL DIAGRAM ShOWING "INCURVED FLAKING." reproduce it. The flakes are usually "edgestruck," and not "plane-struck." On the whole I am inclined to think it is due to reverse flaking. It may be due to pressure-flaking, but the surface ripplings are sometimes exceptionally strong, and the bulbs of percussion are discordant with the effects of pressure so far as these are known to me, and agree fairly well with the effects of reverse flaking.

The comparison of the technical characters of flaking and chipping by different methods is dealt with in Part II, and illustrated in Plate XXXIX, Figs. 4 to 7.

\section{Thy Effects of Crushing and of Differeantial Movement under Pressure.}

If a flint of tabular or plano-convex form be placed with its edge resting on another stone, as shown in the diagram (Fig. 8), and pressure be brought to bear upon it in the direction of the arrow, a series of chips may be removed from its edge as shown by the dotted lines.

It may be observed in the operation of this edge-chipping by pressure, that the chips removed in an early stage of the process usually strike as far back as they ever go, as seen in the chip $a x$ in the diagram (Fig. 9). A prolonged 
continuance of the action only results in the blunting of the edge, to $c x$. If, however, the pressure under which the work is being done be increased, a fresh set of chips; $d y$ to $f y$, will fly off.

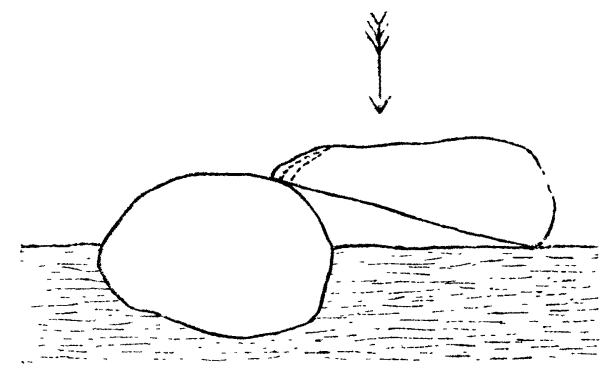

FIG. 8.-DIAGRAM ILLUSTRATING THE PRODUCTION OF EDGE-CHIPPING IN A FLINT BY PRESSURE AGAINST ANOTHER STONE.

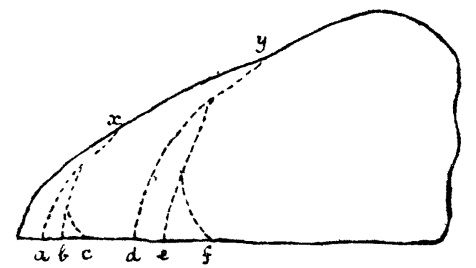

FIG. 9.-DIAGRAM ILLUSTRATING THE "DEPTH OF CHIPPING" UNDER A LESSER AND A GREATER PRESSURE.

In measuring the work done upon a flint under any given pressure, I have taken the perpendicular measuremeut from $x$ or $y$ to the basal plane, irrespective of the length of such lines as $a x$ or $b x$. I propose to speak of this perpendicular as the depth of chipping.

The methods employed for obtaining the necessary pressure have been :(1) By pressing or stamping with the heel of one's boot. (2) By the sudden shock of falling iron weights. (3) By the similar shock of pieces of timber falling under the action of gravity. (4) As 3, but pressed down by muscular effort. (5) By pressure slowly applied in a screw press. (6) By the crushing action of cart wheels. (7) By the drag of a sled loaded under various weights; this gives a reversal of the relative positions of the rounded stone and the edge of the flint to be chipped.

The above processes represent considerable variety in the method of application of pressure, or crushing force, and it is important to note that they all give indistinguishable results.

It is remarkable that a single application of pressure, even if lasting only for a fraction of a second, results in many cases in the removal of a surprising number of small chips, each one leaving a facet behind it. This is especially the case where there is a slip between the two surfaces when the pressure is applied and where the underlying stone has a rough surface, as this greatly facilitates the chipping.

Under the conditions indicated, there is usually a certain amount of slip or movement between the two surfaces which are in contact when the pressure is applied. Dead crushing without movement may, however, produce edge-chipping, provided the force be applied at the right point on or near the edge. This often happens in the case of cart-wheel crushing. But this method in the application of pressure is not generally so favourable for the production of edge-chipping as that of differential movement under pressure. For in the latter case the force tends to 
become automatically applied in the right manner and place (that is, on the edge of the flint), as the two stones forcibly grind across each other.

If forces of dead crushing without movement act centrally upon a flint from two, three, or more directions, and if the resultant force be sufficient to break or crush it, cones may develop at each pressure-point. These cones are usually strong, and the fractures springing from them not infrequently intersect each other and split the flint up in a very complicated manner, many of the fragments assuming the well-known prismatic form (see Fig. 10). If there are only two pressure-points, the flint will often split in half, with two cones (one above and one below) corresponding to the two pressure-points.

The forms produced by the seven methods referred to above are dependent partly upon the original shape of the raw material, and partly upon the form of the underlying surface against which it is crushed. When this underlying surface is convex, the resultant edge-chipping is concave. When the underlying surface is flat, and the original shape of the raw material permits of it, the chipped edge may be straight; where the former is concave, the chipped edge may be convex.

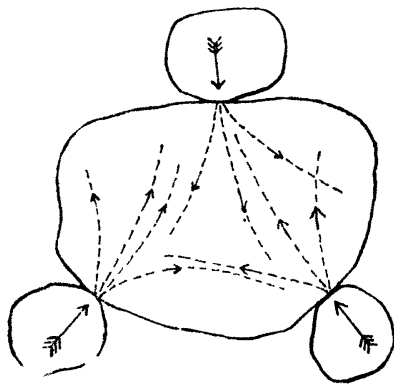

FIG. 10.-DIAGRAM SHOWING THE OPERATION OF PRESSURE ACTING CENTRALLY UPON A FLINT FROM POINTS OF CONTACT WITH SURROUNDING STONES.

Where the underlying surface is irregular, or where it is formed of two pebbles close together, particularly interesting forms are produced. In the latter case especially there will be two chipped concavities with an intervening point between them.

Again, if a concavity be crushed out of the edge of a tabular piece of flint, and then it be turned over and another concavity be crushed out from the opposite side a little distance from the first, a curiously drill-like point with reversed chipping will result.

Characteristic examples of these various forms produced by crushing are illustrated in Plates XXXIX and XL.

The results which I had obtained between the years 1900 and 1905 by several of the above-mentioned methods have already been described in Man, 1905 (103) and 1906 (3), and in the Journal of the Anthropological Institute, vol. xxxv, 1905, pp. 337-364, Plate XXVI. The last method referred to, namely that of the sled, requires some further explanation. The flints to be experimented upon were placed in pigeon-holes in a wooden frame, and then pebbles fixed in the bottom of a sled were drawn over their projecting edges. A box was nailed upon the upper part of the sled in which weights could be placed, while the sled itself weighed originally 20 kilogrammes (44 pounds), but after some reconstruction it weighed $17 \cdot 75$ kilogrammes. The arrangement will be made clear from Fig. 11, where the arrows represent the vertical and horizontal forces brought into play: the latter being supplied by the pulling of one man with a block-and-fal giving a mechanical 
advantage of from 2 to 5 according to the number of "sheares" brought into use.

In comparison with the theory of chipping by soil-abrasion (the active process of solifluction) under pressure, it is particularly useful that the sled experiments separate the vertical pressure from the horizontal traction. It is important to consider the relations between $a, \beta$, and $\gamma$, chipping in this class of experiments. Hitherto we have been dealing with $a$ chipping only, as illustrated in Figs. 8 and 9 . But if the plano-convex flint be placed in the reverse position, with its convex side against the other stone, the two surfaces tend to slip away from each other when pressure is applied. This is illustrated in Fig. 12, where the upper arrow indicates

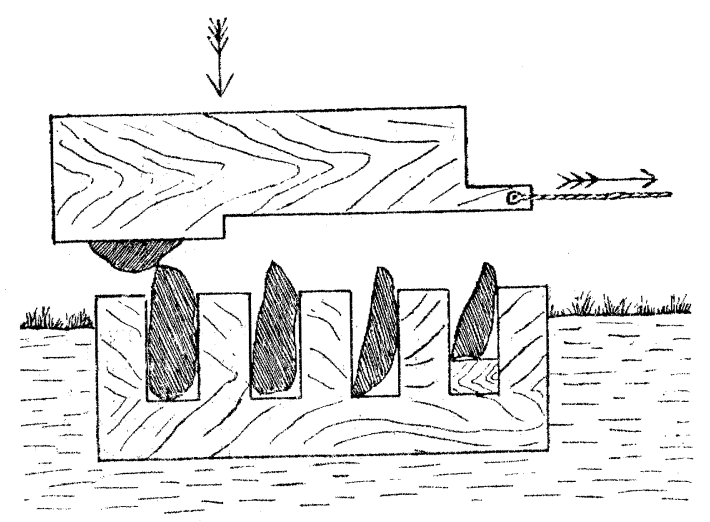

FIG. 11.-DIAGRAM SHOWING (IN SIDE VIEW) THE ARRANGEMENT OF THE SLED EXPERIMENTS.

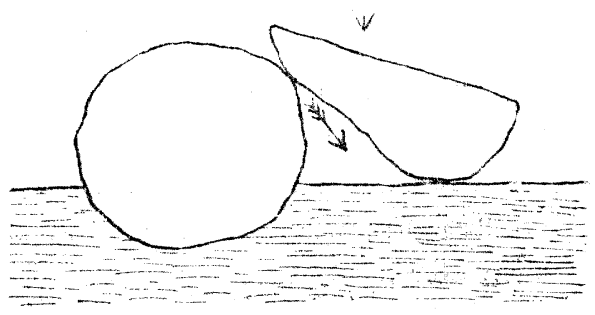

FIG. 12.-DIAGRAM ILLUSTRATING THE POSITION OF "SLIDE" WITHOUT CHIPELNG.

the application of the force, and the lower arrow the direction of the slip. That is to say, there is no effective "grip" between the two surfaces.

I first suggested this principle in the papers published in 1905 , but to Mr. F. N. Haward belongs the credit of having given it the graphic name of "chip-and-slide."

It will also be understood that it is not generally easy, except sometimes in the case of a very thick flint, to obtain true $\beta$ chipping with a plano-convex flint under pressure, because the equilibrium between the two stones in the edge-to-edge position is unstable, and they tend to slip past each other. With regard to $\delta$. chipping, the flints under operation not infrequently snap across by "hingefracture," but true $\delta$ chipping would require enormously greater pressure than a chipping.

Thus the general principles governing the production of $a, \beta, \gamma$, and $\delta$ chipping are of equal importance under the operation of pressure, to that which we found them to be with concussions.

1 "The Chipping of Flint by Natural Agencies," Proc. Prehist. Soc. East Anglia, vol. i, 1912, p. 185. Also "The Problem of the Eoliths," ibid., p. 347. 
Before closing this branch of the subject, there are two other points of some interest, namely, the special conditions presented by a plano-convex flint with an original notch in its edge; and that of the tabular flint. In the former case we might be led to imagine that the original hollow would be the protected part. In the operation of concussions this doubtless is the case, as a general rule, but under the operation of movement under pressure, the "attacking" pebble slides into such an original notch, obtains an increased "grip" in that situation, and as a consequence does more execution. This is illustrated in Fig. 13, with the resultant edgechipping suggested by dotted lines.

In the case of tabular flint, true $\delta$ chipping does not exist, but a chipping may occur with equal facility in either direction. 'This comes into instructive comparison with the Kentish eoliths.'

In general summary of movement under pressure upon plano-convex or tabular flint, it is particularly noteworthy that the effects obtained are in conformity with a series of well-defined "types." Of this gr,up of "types" the notch, or pseudo-hollow-scraper, is the central point, and dominant over everything else. In the one direction, the notch becomes shallower, and passes through the straight edge to the outward curve, or pseudo-scraper, or to mere indefinite edge-chipping. On the other side the notch is found either double, or double-reversed (the pseudo-drill), or it occurs in combination with other edge-chipping.

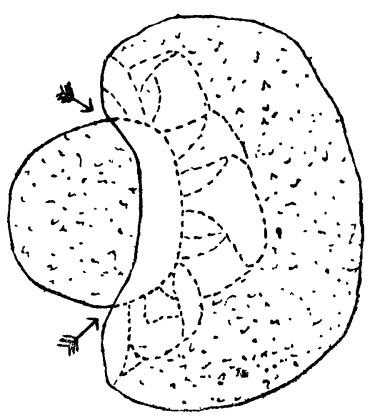

FIG. 13.-DIAGRAM SHOWING IN PLAN THE INCREASED GRIP OBTAINED IN AN ORIGINAL HOLLOW IN THE EDGE OF A FLINT, WITH THE RESULTANT EDGE-CHIPPING SUGGESTEN BY DOTTED LINES.

In the effects of concussions we have already noted the influence of selective $a$ chipping; but the results of concussions, as a whole, are less systematic, and generally inferior to those obtained by pressure. If forces of greater violence be brought into play, the effects break away from what one may describe as the systematic restraint automatically imposed by the influence of $\boldsymbol{a}$ chipping, and very astonishing results may occasionally be produced. But at the same time, that which is gained in exceptional cases by a deceptive appearance of control of the angles is lost by its sporadic uncertainty, and by the absence of system in the group.

In carrying on experiments under pressure, year by year, one finds that the same group of forms repeat themselves indefinitely in the results obtained, and that these results are indistinguishable from the eolithic forms.

\section{Application of tie Study of Flint Fracture to the Problem of THE EOLITHS.}

(a) The Eoliths of Kentish type.

In applying the results obtained by the study of flint fracture to the problem 
of the human or natural origin of the eoliths, one must undoubtedly proceed with caution.

In considering the problem of chipped flints of doubtful origin one has to take into account:-

(1) Whether the chipping shows conscious control of the material, or whether it follows the planes of least resistance only (particularly the $a$ and $\beta$ chipping).

(2) Whether the forms of the chipped flints are conceivably useful as implements.

(3) Whether the characters of the chipping (disregarding size) agree with those observed in that produced experimentally by $(a)$ human flaking, (b) mechanical concussions, $(c)$ dead crushing, $(d)$ differential movement under pressure.

(4) Whether there is associated evidence of (a) contused surfaces indicating concussions by water abrasion, $(b)$ striated surfaces pointing to movement under pressure by ice or soil-abrasion.

With regard to the first point, it is not possible to hold two opinions upon the fact that the chipping upon the Kentish eoliths follows the planes of least resistance only, and does not show control. At the same time this does not prove that they are not human implements, because if man existed at this early time he might not yet have acquired the skill necessary to enable him to control the angles of chipping.

Upon the second point, the Kentish eoliths as a group are not, to my mind, very convincing as implements, although some of them might be useful. This, however, does not prove that they are implements, because many natural stones are capable of serving as excellent implements. In fact, I think one might say that so long as man remained unable to control the flaking angles, to some degree at least, naturally broken stones would make as good implements as anything that he could chip for himself.

With regard to the third point, there can be equally no question that the characters of the Kentish eoliths agree with the results of mechanical movement under pressure. The same forms can be imitated by hand-chipping if a method of lifeless knock-knock-knock of one stone against another be adopted. But it requires-if the apparent contradiction can be understood-a carefully controlled absence of control in the manipulation. If this process of lifeless and mechanical knocking be carefully maintained, I am not sure that the results can be distinguished from the effect of mechanical movement under pressure. But the numerous and special characters common to the eoliths and to these particular mechanical effects, cannot be reproduced by that free delivery of sharp blows which it appears to me would be the technique most simply and naturally adopted by primitive man. 
In discussing the Kentish eoliths I take the Prestwich collection now in the British Museum of Natural History to be the type series, and I have to thank Dr. A. Smith Woodward, F.R.S., for the facilities that he has given me for its. examination. My remarks have no application to anything that is not in accordance with this series.

The fourth point must now be considered, namely, whether it is reasonable to. suppose that the necessary forces to produce edge-chipping have actually been in operation in superficial drift deposits. ${ }^{1}$ It is sufficiently obvious that the weight of a bed of sand or clay remains a static force which is powerless to injure the most fragile shell (when this is filled with the same material), so long as no movement takes place.

It is my opinion, and I think that most field workers will agree with me, that in the ease of drifts at high elevations clinging to the sides of hills, movement has been widely in operation. Nor is this action confined to hilly districts, or to districts with soluble calcareous sub-soils. Mr. W. Shone dealt with the subterranean erosion of non-calcareous deposits, and the consequent foundering of the superincumbent beds, in a paper brought before the Geological Society in 1892.2 I have also given additional illustrations in the paper previously referred to. ${ }^{3}$

But I think we can go further than these generalities, and find direct evidence to support their application to the case in point. The present writer has. previously drawn attention to the evidences of differential soil movements, furnished by the striated surfaces which are so commonly associated with the eoliths in the field.

It appears to me that this evidence is conclusive, for I do not know by what means, except by movement under pressure, the scratching of the surfaces of stones. can be effected.

It is noteworthy that the scores passing across the surface of the flints are sometimes directly associated with the notches which I believe to have been squeezed out of their edges by the same force.

(b) The Sub-Crag flints.

In considering the effects of crushing on a larger scale and under greater. pressure, one is confronted with serious practical difficulties.

It is not possible to work experimentally under pressures which are comparable with those that obtain beneath an ice-sheet, or even beneath a considerable thickness of sand or clay, without the aid of power, and the erection of expensive plant. I greatly question if such expenditure would be justifiable, even if a sufficient grant could be obtained from some public body having financial resources. at its disposal for purposes of scientific research.

1 The quantitative consideration of this problem is discussed in Part II.

2 W. Shone, Quart. Journ. Geol. Soc., vol. xlviii, 1892, pp. 96-103.

3 S. H. Warren, Journ. Anthrop. Inst., vol. xxvi, 1905, pp. 349-357. 
For my own part I am content to consider the reasonable probabilities of the case in arguing from the known smaller to the unknown greater.

Many of the general points referred to under the heading of the Kentish eoliths apply equally well to the case of the sub-crag flints. In fact many eoliths of Kentish type occur in the basement bed of the crag, although these are not the most notable or conspicuous of the series, at least not so far as size is concerned. So far as this smaller edge-chipping of the sub-crag flints, and that of the Kentish eoliths, is respectively concerned, I see no possibility of escape from the general proposition that whatsoever is the origin of the one is also the origin of the other.

In the "rostro-carinates" we are presented with an extreme development of the eolithic form which is but rarely seen under other circumstances, except in a comparatively diminutive size. But where greater forces are operating upon bigger material I do not think that the consideration of size is important. The close association of this type with the familiar notches-with-point, which are so characteristic of the effects of pressure, is illustrated in Figs. 4 to 10 of Plate XL, and I will leave these illustrations to speak for themselves.

Upon the relative merits of the sub-crag, and of the Kentish eoliths, opinion is strangely divided. My friend,Mr. A. Santer Kennard,F.G.S., while still continuing to maintain his belief in the Kentish eoliths, strongly repudiates the claims of the sub-crag flints. Upon the whole, however, I am inclined to think that opinion is more favourably disposed towards the sub-crag flints than it is towards the Kentish eoliths.

For my own part, as I go backwards and forwards from the Prestwich collection of eoliths at South Kensington, to the collection of sub-crag flints deposited by Sir Ray Lankester at Bloomsbury, I can only say that whichever series I examine the last always appears to me, from the point of view of being human implements, as the more incredible :

But to return to the suggested points of inquiry set forth at the beginning of the discussion upon the Kentish eoliths. Of these, the question of control is one of supreme importance.

The "rostro-carinates" are admirable examples of chipping along the $a$ and $\beta$ planes of least resistance, ${ }^{1}$ while the technical character of the chipping is also in agreement with that observed in the operation of mechanical pressure.

A certain number of the sub-crag flints, however, are more suggestive of control, although they do not belong to systematic types. It may be that these are the sporadic products of violent concussion rather than the effects of pressure. But it is not upon these aberrant forms that the greatest stress is laid. The more

1 Sir E. Ray Lankester, "Description of the Test Specimen of the Rostro-Carinate Industry found beneath the Norwich Crag," Roy. Anthrop. Inst., Occasional Paper, No. 4, 1914. That the rostro-carinate form is produced by chipping along the planes of least resistance is confirmed by the evidences of its evolution upon a modern sea beach, described by Professor Sollas before the British Association in 1913. 
systematic types make a stronger appeal, although as a matter of fact they are more easily explained upon a mechanical basis. The aberrant types are the product of such absolutely fortuitous causes that they defy detailed explanation. The systematic $a$ and $\beta$ chipping is on the other hand the inevitable result of the operation of certain definite forces acting upon raw material of certain definite forms.

On the more personal side I may explain that for some years past I have been searching for Palæolithic implements in the gravels of the Tendring Hundred of Essex In addition to the implements, I found many chipped flints, which, as I saw them on the ground, I took to be also human implements, but upon closer examination I came to the conclusion that they were non-human. One of these in particular was extraordinarily like a Mousterian point, but it was yet in my opinion definitely non-human in origin.

I had been noting these remarkable chipped flints for some years, before the sub-crag flints were known to me ; now that I have come to recognize the mineral condition and the chipping of the sub-crag flints of Ipswich, it is quite clear that those from the Essex gravels are sub-crag derivatives. I mention this to show that my judgment of the sub-crag flints, whether right or wrong, is not a matter of prejudice based upon their date, but is one which I formed upon the intrinsic merits of the flints themselves without knowing them to be earlier than the Palæolithic Age.

With regard to the associated field evidences of the sub-crag flints, the proofs of the operation, of mechanical forces in the shape of contusion, powerful striation, and the like, are generally recognized. I hold the unequivocal opinion that whatever force produced the scratching would be equally capable of effecting the chipping.

\section{The Harefield Section with Flint Chipping by Sub-soil Pressure.}

Upon the occasion of the visit of the Geologists' Association to the works of the British Portland Cement Company on April 26th, 1913, I found some instructive evidences of the sub-soil chipping of flint by the pressure of the superincumbent strata. The pit is situated near the village of Harefield, and shows the Reading Beds and base of the London Clay overlying the chalk. The aciual thickness of the Tertiary Beds varies with the configuration of the overlying surface, but it must have reached, or exceeded, one hundred feet within comparatively recent geological times. It is the operation of the pressure due to this great thickness that is recognized in the results.

At one part there is a variable and irregular bed of flint gravel, up to six feet or rather more in thickness, at the base of the Tertiaries.

The top of the chalk is riddled with tubular borings which have given rise to some discussion, but by whatever organisms they were made, there can be little doubt that the borings were effected when the chalk surface formed the floor of 
the Eocene sea. There is also no residual green-coated band seen in this section. It is then clear that the maximum amount of chalk which has been removed in solution since early Tertiary times is limited to a very few inches. This has an important bearing on our subject.

A considerable proportion of the flints composing the basement gravel of the Tertiaries are broken by the pressure which they have exerted upon each other, some being almost reduced to powder. It is very instructive to dig these stones out and observe the shattered cones which have been developed at points of contact between them, as indicated in the diagram (Fig. 10). There can, I think, be no question that vibration, or other stress, has been set up within the mass of this gravel, to convert the static force of pressure in equilibrium into a dynamic force capable of doing work. This stress has probably been caused either by earthquakes, by changes in volume due to variation of temperature or moisture, or to the very slight amount of solution of the chalk surface which has probably taken place. But there has been no perceptible movement or displacement. Many of the broken flints are still so closely held together that one cannot see that they are broken until one touches them.

Among the broken flints, many good bulbous chips, still remaining in the facet upon the parent block, may be found. In some cases notches have been squeezed out of the edges of the flints, and occasionally the edges are chipped in a manner which is very suggestive of human work, as illustrated in Plate XL, Figs. 11, 12, 13.

The chipping presents certain special features and differs from that of the Kentish eoliths, and also from that of the sub-crag flints. The special character of the chipping is due to three main causes: (1) the character of the raw material, (2) the strength of the force, (3) the comparative absence of movement. On these points one may observe that the raw material consists largely of Tertiary pebbles, and even when this is not so it is often of poor flaking quality. On the second point, the strength of the force has been so great that the ultimate depth of chipping is never reached, but free chipping at various angles, according to the incidence of the pressure, continues throughout. ${ }^{1}$ While thirdly, the special characteristics produced by movement under pressure are for the most part wanting, as so little movement has taken place.

'Thus the notches are usually squeezed out in one or two larger chips only, instead of in many small chips, as we find in movement under a comparatively small load of pressure.

Still, a search of a few hours in the section will generally reveal examples of chipping which has a close resemblance to supposed human work. If the comparative absence of movement brings its limitations, it has the unique advantage of leaving the chips in contact with the parent blocks. If more movement had

1 Measurement of 34 chipping angles gave a range of from $43^{\circ}$ to $92^{\circ}$, with only a slight. concentration between $60^{\circ}$ and $70^{\circ}$. 
occurred there would have been a larger amount of good chipping, but the chips would have become separated, and the extreme enthusiast, in spite of the palæontological improbability of the existence of man in the Lower Eocene period, might still have claimed them as human implements.

In following this class of evidence, the fact that movement gives the best chipping but separates the chips, imposes certain limitations from which I am afraid there is no escape.

I would, however, particularly draw attention to the important evidences regarding a "Nature's workshop" site described by Mr. F. N. Haward. ${ }^{1}$

\section{General Objections against the Eoliths.}

One of the general difficulties against the acceptance of the eoliths as human implements, which weighs with me almost more than any other, is their extraordinary evolutionary history.

It may be stated as a general rule that the group of eoliths found in any deposit is independent of the age of that deposit.

It is true that in some cases earlier deposits contain more primitive eoliths than later deposits, but this is not uniformly the case. Quite as often the reverse is found to hold, and eoliths of advanced form are found in earlier deposits of the Tertiary period and eoliths of primitive form in later deposits.

My friend Mr. Arthur Wrigley made a considerable collection of eoliths from the Low Level gravels of the Lea Valley, which are later than the Mousterian epoch (and I have also found many myself) which are of very primitive form, and compare in a remarkable manner with those from the Elephas meridionalis bed of Dewlish; while many of the eoliths from Miocene, Oligocene and Eocene strata are of far more advanced forms.

The evidence seems to point to the conclusion that either primitive or advanced eoliths may occur equally in deposits of all ages where suitable material exists for their production, and where this material has been subjected to the right forces.

This is a most extraordinary state of things, in view of the theory of their human origin, but that which we should expect if, as I believe, they are due to natural causes.

Another difficulty is found in the fact that prehistoric implements have sometimes been converted into eoliths subsequently to their patination.

Mr. W. Cunnington was the first to point out that there are eoliths from the Kent plateau, ${ }^{2}$ differing in no way either in chipping or in patination from those supposed to be pre-Palæolithic, which are yet made out of old abraded and broken

1 F. N. Haward, "The Chipping of Flints by Natural Agencies," Proc. Prehist. Soc. East Anglia, vol. i, 1912, p. 185. See also the important evidences to a similar effect described by the Abbé H. Breuil, L'Anthropologie, T. xxi, 1910, p. 385.

2 W. Cunnington, Quart. Journ. Geol. Soc., vol. liv, 1898, p. 291.

VOL. XLIV. 
palæoliths. Similar facts have also been insisted upon by the present writer, ${ }^{1}$ and more recently by Mr. F. N. Haward.2

With respect to eoliths recently made upon sea beaches and the like, it has been urged against them that they are only temporary forms in the making of the pebble. Surely nothing could be a weaker defence. The pebble is itself but a temporary thing, and gradually gets smaller and smaller, and finally disappears. The question as to whether the edge-chipping upon a flint has been done by Nature or by man does not affect its subsequent fate-whether it may be destroyed by continued abrasion, or whether it may become preserved in a geological deposit. The torrent does not select the chipping of Nature for destruction and preserve the work of man.

The danger of the arguments from similarity of form and from the presence of a hand-grip opposite to the chipped edge has been shown again and again, by Mr. F. N. Haward, Mr. W. H. Sutcliffe, in a previous paper by the present writer, and also by others. ${ }^{3}$ It is so easy to argue in a circle to show that our series of flints indicates intelligence, and not to see that the intelligence has been put into them by ourselves, in our own selection out of the infinite variety of Nature. While with regard to the hand-grip, one must not forget that the adaptability of the human hand is very considerable, and it is inevitable that the thinner and weaker edge of a flint will become accidentally chipped where the thicker and stronger edge opposite to it (forming the alleged hand-grip) will remain comparatively unchipped.

\section{PART II.}

\section{Technical Detalls and Tabulation of Experimental Results.}

The kilogrammetre.-This is the amount of work done in raising one kilogramme to a height of one metre against gravity: two kilogrammetres being equally the work of raising two kilogrammes one metre, or of raising one kilogramme two metres. The equivalent English measure is the foot-pound (not the foot-poundal); it is similarly estimated: one foot-pound being equal to $0 \cdot 1383$ kilogrammetres.

Momentum.-The power of doing work possessed by a moving body depends upon its momentum, which is the product of the mass into the velocity : the same mass having four times the power of doing work when travelling at twice the velocity.

1 S. H. Warren, Journ. Anthrop. Inst., vol. xxxv, 1905, p. 344, and plate xxvi, figs. 2 and 3.

2 F. N. Haward, Proc. Prehist. Soc. East Anglia, vol. i, 1913, p. 347.

${ }^{3}$ F. N. Haward, Proc. Prehist. Soc. East Anglia, vol. i, 1913, p. 353, etc. W. H. Sutcliffe, Mem. and Proc. Manchester Lit. and Phil. Soc., vol. lvii, 1913, No. 7. For further criticisms on general points, and references to the literature of the subject, vide $\mathrm{S}$. H. Warren, Man, 1913 (20), and Geological Magazine, 1914, p. 546. 
Kinetic energy.-The true vis viva, or kinetic energy, is calculated by the formula

\section{$\frac{1}{2} \mathrm{MV}^{2}$}

where $\mathrm{M}$ is the mass and $\mathrm{V}$ the velocity. This calculation of kinetic energy may be based upon any units of measure that may be chosen, that adopted here being one kilogramme (or one pound), as the unit of mass, and one metre (or one foot) per second as the unit of velocity. Strictly speaking, these units of mass are only accurate so long as the force of gravity remains constant, which for our present purpose we may assume. This basis of calculation gives the kinetic energy in watts (or foot-poundals); 1 watt being equal to $23 \cdot 72$ foot-poundals.

Falling bodies.-The experiments upon the chipping produced by the impact of one stone against another, have been conducted by releasing stones from a measured height and leaving them to fall under the acceleration of gravity. This is a very convenient method, as it enables the necessary calculations to be made. As we cannot measure the time, and do not need to do so, the formulæ most usually given may be modified, so that the velocity $(V)$ can be calculated directly from the height of fall, or space traversed $(s)$, and the acceleration $(g=9.81$ metres or $32 \cdot 19$ feet in London); thus :-

$$
\mathrm{V}=\left(\sqrt{\frac{s}{\frac{1}{2} g}}\right) g
$$

The following table will give a general idea of the relations of the factors with which we are dealing, and the range covered in the tabulated effects of concussions.

\section{TABle I.-Falling Bodies. ${ }^{1}$}

\begin{tabular}{|c|c|c|c|c|c|c|c|}
\hline \multicolumn{2}{|c|}{ Weight of body. } & \multicolumn{2}{|c|}{ Height of fall. } & \multicolumn{2}{|c|}{ Velocity per second. } & \multicolumn{2}{|c|}{ Kinetic energy. } \\
\hline Kilogrammes. & Pounds. & Metres. & Feet. & Metres. & Feet. & Watts. & $\begin{array}{c}\text { Foot- } \\
\text { poundals. }\end{array}$ \\
\hline $0 \cdot 0068$ & $0 \cdot 015$ & $1 \cdot 83$ & $6 \cdot 0$ & $6 \cdot 00$ & $19 \cdot 65$ & $0 \cdot 122$ & $2 \cdot 9$ \\
\hline $0 \cdot 0454$ & $0 \cdot 1$ & $0 \cdot 76$ & $2 \cdot 5$ & $3 \cdot 86$ & $12 \cdot 7$ & $0 \cdot 34$ & $8 \cdot 06$ \\
\hline $0 \cdot 272$ & $0 \cdot 6$ & $2 \cdot 44$ & $8 \cdot 0$ & $6 \cdot 9$ & $22 \cdot 7$ & $6 \cdot 5$ & $154 \cdot 5$ \\
\hline $0 \cdot 326$ & $0 \cdot 7187$ & $0 \cdot 61$ & $2 \cdot 0$ & $3 \cdot 46$ & $11 \cdot 35$ & $1 \cdot 95$ & $46 \cdot 3$ \\
\hline $0 \cdot 557$ & $1 \cdot 229$ & $1 \cdot 37$ & $4 \cdot 5$ & $5 \cdot 19$ & $17 \cdot 0$ & $7 \cdot 5$ & $178 \cdot 0$ \\
\hline $1 \cdot 44$ & $3 \cdot 187$ & $1 \cdot 68$ & $5 \cdot 5$ & $5 \cdot 73$ & $18 \cdot 75$ & $23 \cdot 6$ & $560 \cdot 0$ \\
\hline $5 \cdot 17$ & $11 \cdot 4$ & $0 \cdot 102$ & $0 \cdot 33$ & $1 \cdot 41$ & $4 \cdot 63$ & $5 \cdot 14$ & $122 \cdot 5$ \\
\hline
\end{tabular}

1 In this table, and also in those which follow, the equivalent values in the English and the metric systems are given side by side. 
The pressure of impact.-The pressure of a blow is theoretically estimated by the relation between the kilogrammetres (or the foot-pounds) possessed by the striking body, and the distance through which it is brought to rest. A moving body striking with a force of 10 kilogrammetres and brought to rest within a distance of $\frac{1}{100}$ metre, is said to exert a pressure of $10 \times 100=1,000$ kilogrammes. If it had been brought to rest in $\frac{1}{1000}$ metre, it would have exerted a pressure of $10 \times 1,000=10,000$ kilogrammes, and so on in similar proportions.

Thus in experiments in flint chipping we must bear in mind the fact that the effective pressure of the blow will depend upon the resilience (or modulus of elasticity) of the support on which the flint is placed to be operated upon. In experiments upon " direct concussions," I have used a considerable variety of support, hard dry clay, resilient turf, soft wet gravel, and the like, while sometimes the flint to be operated upon has been held in the jaws of a screw press. I have been so far unable to eliminate the influence of the support. When working under otherwise similar conditions (kinetic energy, velocity, quality of material) the results obtained certainly come within the same general limits of variation, both as regards size and characteristics; the only exception being that when working under low velocities of less than three metres per second it is very difficult to obtain a chip of any kind upon a loosely placed flint. Under these low velocities it is practically necessary for the flint to be firmly placed, or it is only pushed on one side. This limitation does not apply to "reverse concussions."

There are also other factors, such as the area of contact of the two surfaces at the moment of impact, which have their influence, but which under practical conditions it would be difficult to estimate.

Estimated favourable result.-With regard to the foregoing points, in dealing with a considerable number of experiments I have taken the average maximum of the effects. By this means the accidental association of unfavourable conditions is eliminated, and the results of the accidental association of favourable conditions are brought together under the various forces used.

There was some difficulty in obtaining a just average. For instance, in the case of the higher pressures shown in Table III, a number of the flints used were too thin, and would have given the same depth of chipping under a lower pressure. The difference in effect being that, under an excess of pressure, chipping tends to continue at the lower angles, and the later chips ( $c x$ or $f y$ of Fig. 9) do not occur. Thus an actual average of the results would have been too low, as a fair average, while the "estimated favourable result" represents a nearer approximation to that which it professes to be. This quantity may seem rather vague, but practical experience shows that it justifies itself. In conducting a series of these experiments over a course of years, there is found to be an average maximum result which is comparatively constant, and which is only rarely exceeded to any considerable extent.

Concussions. - Table II shows the size of chip obtained by mechanical concussions acting along the planes of least resistance. The vertical abscissæ represent the 


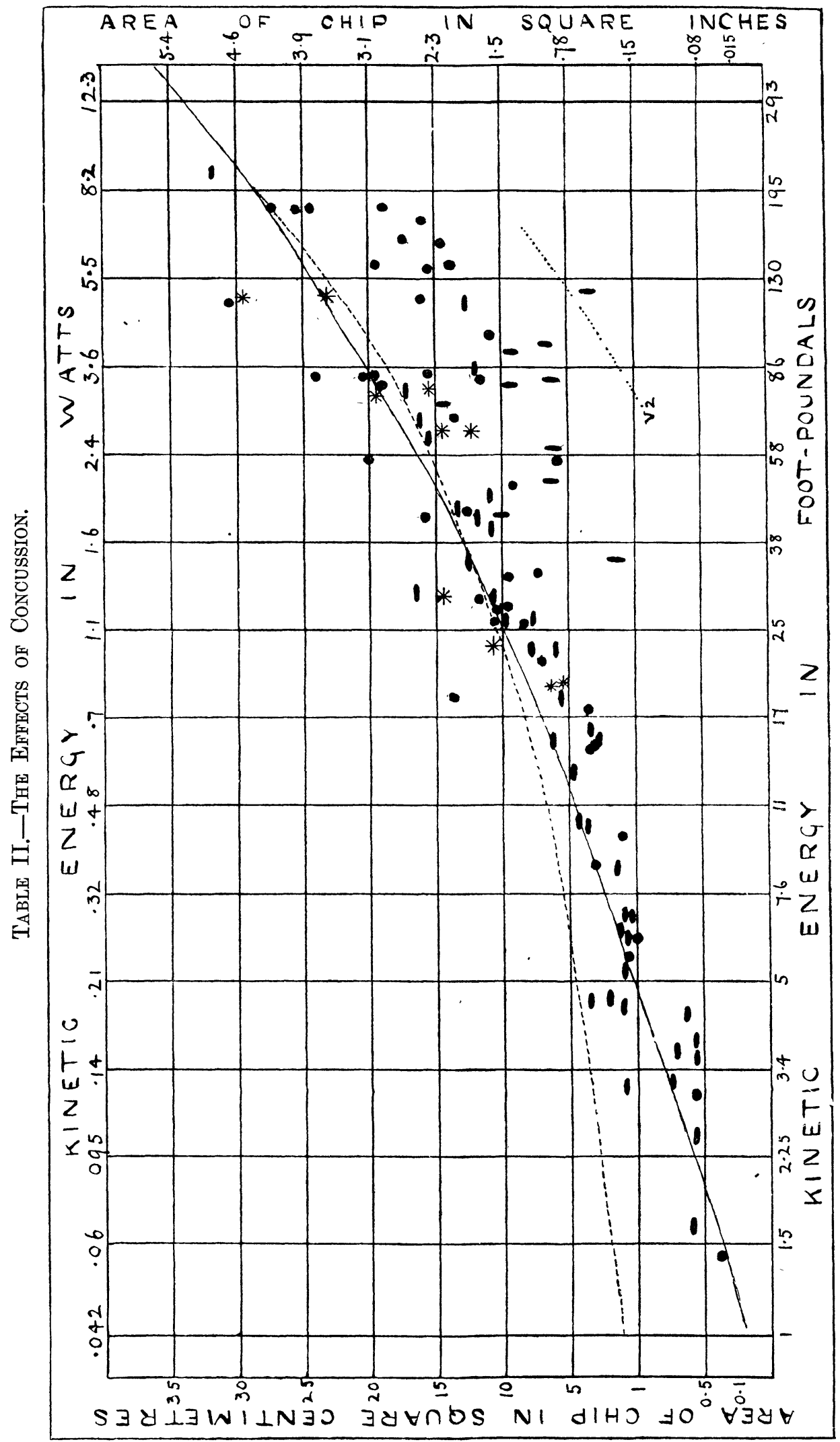


kinetic energy, with the equivalents in the metric and the English systems above and below. In order to obtain the relative space required to show the results, these are arranged in the geometrical progression of $1: 5$. The horizontal ordinates represent an approximate estimate of the area of the fractured surface of the chip (which is less than the multiple of the length and breadth), in square centimetres and the equivalent in square inches, on the left and right.

The records show the best results obtained in different series of experiments, the smaller chips obtained at the same time not being represented. These would have entirely filled up the lower right-hand portion of the table, and would have prevented an important point from being shown.

All these results, with the exception of that below the line marked " $\mathrm{V} 2$ " (which is also a best result from a series of experiments) are for impacts delivered at velocities of between 3 and 7 metres per second.

The circular dots represent " direct concussions" upon flints placed in a slight hollow in the ground; the perpendicular oval dots represent "direct concussions" upon flints held in the jaws of a screw press; the horizontal oval dots represent "reverse concussions"; and the stars " direct concussions" upon Brandon flint. It will be noted that these all fall within the same group.

Among this group of experiments there is one result standing entirely alone, namely, a chip of about 65 square centimetres area made by a kinetic energy of 9.4 watts. This is nearly twice the size of the " estimated favourable result." This result could not be included in the table without greatly reducing the scale on which it was drawn. Such exceptional effects should not, however, be lost sight of in our broader view of the problems involved.

Pressure.-Table III shows the results of movement under pressure (sled crushing). The outer scales for the vertical abscissæ represent the total load of the sled, the inner scales the estimated working pressure. The latter estimate is based on the fact that the total load is distributed over 2,3 , or 4 points of support, according to circumstances; this is taken at a maximum of two-thirds of the total load.

The horizontal traction is not shown on the table. From experiments made with this object, I found that up to a load of about 45 kilogrammes the force of traction necessary to draw the sled over the uneven edges of the flints was about equal to the total weight of the loaded sled. From observation of the progress of the work, I think that the greater part of the force of traction not infrequently operates upon one edge.

The horizontal ordinates show the depth of chipping upon the principle already explained.

The black circles represent the effects upon drift flint; the stars upon Brandon flint. The open circles are a series of measurements of the depth of chipping of 37 selected examples of the eoliths in the Prestwich collection, including the smallest and the largest. With one exception they are placed as a chain upon the line of the estimated favourable result. 


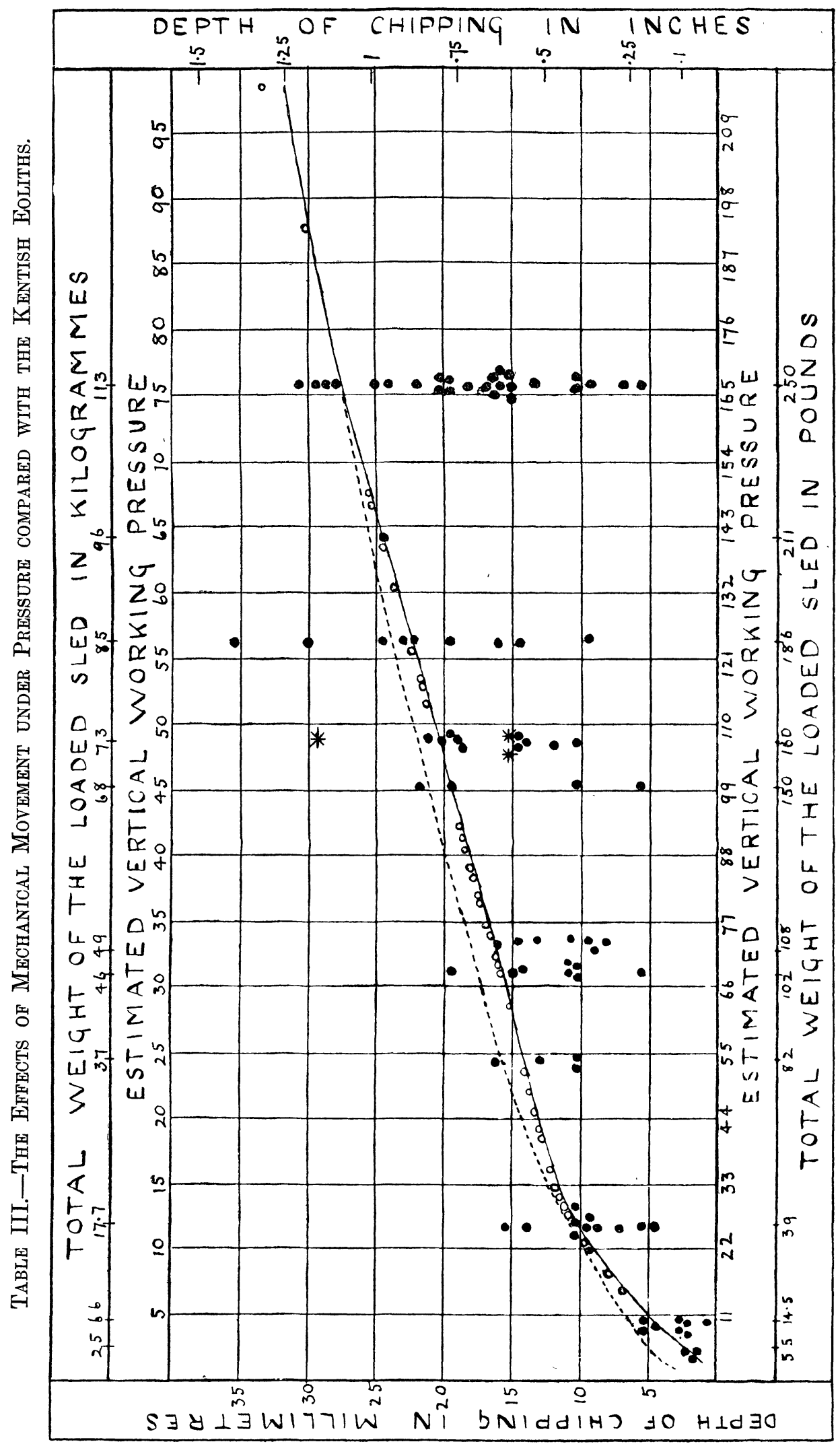


Table IV.-Area of Chip obtained by Pressure.

\begin{tabular}{|c|c|c|c|c|c|}
\hline \multicolumn{2}{|c|}{ Estimated total pressure. } & \multicolumn{2}{|c|}{ Area of chip. } & \multirow{2}{*}{$\begin{array}{l}\text { Ratio of } \\
\text { pressure. }\end{array}$} & \multirow{2}{*}{$\begin{array}{l}\text { Ratio of } \\
\text { size of chip }\end{array}$} \\
\hline Kilogrammes. & Pounds. & $\begin{array}{c}\text { Square } \\
\text { centimetres. }\end{array}$ & $\begin{array}{l}\text { Square } \\
\text { inches. }\end{array}$ & & \\
\hline 139 & 306 & $8 \cdot 0$ & $1 \cdot 24$ & $1 \cdot 0$ & $1 \cdot 0$ \\
\hline 101 & 222 & $6 \cdot 0$ & $0 \cdot 93$ & $1 \cdot 375$ & $1 \cdot 33$ \\
\hline $89 \cdot 5$ & 197 & $4 \cdot 0$ & $0 \cdot 62$ & $1 \cdot 56$ & $2 \cdot 0$ \\
\hline $57 \cdot 3$ & 126 & $2 \cdot 75$ & 0.425 & $2 \cdot 42$ & $2 \cdot 9$ \\
\hline $43 \cdot 5$ & 96 & $2 \cdot 0$ & $0 \cdot 31$ & $3 \cdot 18$ & $4 \cdot 0$ \\
\hline $21 \cdot 2$ & $46 \cdot 7$ & $1 \cdot 0$ & $0 \cdot 155$ & $6 \cdot 54$ & $8 \cdot 0$ \\
\hline $8 \cdot 0$ & $17 \cdot 6$ & $0 \cdot 2$ & $0 \cdot 031$ & $17 \cdot 4$ & $40 \cdot 0$ \\
\hline $3 \cdot 5$ & 7.75 & $0 \cdot 05$ & $0 \cdot 00775$ & $39 \cdot 5$ & $160 \cdot 0$ \\
\hline
\end{tabular}

Table IV is a summary of the size of chip, estimated as in the case of Table II, obtained under various pressures. The effective working pressure is estimated, and cannot be accurately calculated. It must also depend much on the length of contact between the two surfaces, and this is constantly changing as the flint edge chips under the force.

But as the size of chip represents the favourable result obtained from a series of experiments, I assume a favourable concurrence of conditions in the application of the force, and estimate the total pressure (by the parallelogram of forces) as the resultant of the maximum estimated vertical pressure and the maximum estimated traction (= total weight of the loaded sled). It is probably but seldom that this estimate is fully realized, but I think it gives an approximate measure of the necessary force, as applied under practical conditions, to do the work indicated.

Ratio of force to result. - The continuous fine lines in Tables II and III, passing obliquely upwards from left to right, represent the line of the estimated favourable result. The broken lines are drawn to the hypothetical ratio that the results obtained in those two cases vary directly as the square root of the increase of the force. That is to say (in Table II), that with four times the kinetic energy the area of the chip will be twice as large ; and (in Table III) under four times the vertical pressure the depth of chipping will be twice as great. This mathematical ratio is calculated backwards from the higher part of the line of favourable result.

To a certain point, the continuous and the broken lines closely correspond. We are not, however, dealing with the same kind of result in the two cases, for the size of chip removed in the case of pressure approximates to the square of the depth of chipping. Accordingly, if we look to the comparative ratios of the size of chip removed, and of the pressure given in the last two columns of Table IV, we find 
that with the greater pressures the results approximate to the ratio that the size of chip varies directly as the pressure; that is, four times the pressure gives more than four times (instead of twice) the size of chip. Thus the ratio of force to effect is not the same under the operation of pressure as it is in the case of concussions, although it chances to appear so if the depth of chipping in the one case be compared with the area of the chip in the other.

All three ratios, however, break down under the lower forces. In the case of concussions, this breakdown occurs below a kinetic energy of about 1 watt in the case of impacts delivered at velocities of from 3 to 7 metres per second, and also at higher kinetic energies at low velocities of less than somewhere about 2 metres per second, as suggested by the separate line marked "V 2." This line (V 2) has not been satisfactorily worked out, and is only a suggestion. It would be obviously unsound to compare a favourable result under one force with an unfavourable effect under another, and it is peculiarly difficult under such low velocities to establish a favourable result which shall be proportionally comparable with that obtained under higher velocities.

Under pressure the breakdown occurs below the estimated maximum working pressure of about 10 kilogrammes. A similar state of things may be noted in Table IV, where under the lowest force about $\frac{1}{40}$ of the pressure gives $\frac{1}{160}$ of the size of the chip (as compared with the highest force).

Supposing these results to be within moderate limits of error, they seem to suggest that there is something in the nature of a "critical point," above and below which the ratios are different.

If it were justifiable to suppose that the upper ratio would be continued for a considerable increase of pressure beyond that used, we might calculate that a depth of chipping of 60 millimetres would require movement under an effective working pressure of about 370 kilogrammes.

Through the kindness of Sir Ray Lankester I have been enabled to obtain measurements of the series of sub-crag flints deposited by him in the British Museum. The highest depth of chipping (in millimetres) is a rather doubtful record of 62 , but $58 \cdot 7,58$, and $57 \cdot 3$ were also observed; the lowest record being $15 \cdot 3$.

The striation of flint surfaces.-I have made some experiments in the scratching of flints with quartz grit, and find that under pressures of from 6.4 to $9 \cdot 0$ kilogrammes (14 to $20 \mathrm{lbs}$.), considerable scratching takes place, but it is very shallow. When the pressure is increased to 23 kilogrammes (50 lbs.) the scratches become deeper, but are generally fewer in number and very short, owing to the fact that under the greater pressure most of the particles of quartz grit become crushed before they have time to effect any scratching.

I have endeavoured to estimate the depth of the scratching made under a pressure of 23 kilogrammes, by means of the fine focussing adjustment of a microscope reading in thousandths of an inch; if I am not mistaken it appears to be about 0.002 inch or 0.05 millimetres. The deepest scratch I can find in my own 
collection upon a flint implement is about 0.003 inch or 0.075 millimetre, estimated by the same method. I believe that deeper scratches than this occur occasionally on flints from the Kentish plateau, and perhaps more frequently in the basement bed of the crag, and I think that they must have been made by contact with some mineral tougher than quartz grit; at least tougher than that which I have used.

The great majority of the scratches upon the Kentish flints are, however, of a less depth than 0.001 inch or 0.025 millimetre, estimated in the same manner as the above.

Mr. J. Reid Moir ${ }^{1}$ has recently drawn attention to the influence of weathering upon the scratching of flints. The flint surfaces that $I$ used in these experiments were in no case corroded; they were either fresh fractures or slightly patinated (glossy), and were all drift flint.

Doubtless much of the scratching observed upon surface flints, to which attention has been directed by some recent theories, has been caused by agricultural operations. It sometimes occurs upon gun flints which are not more than 250 years old.

Application to natural agencies.-In comparison with the foregoing results, we have now to consider the forces available in Nature to effect chipping.

Table V shows the kinetic energy generated by stones of certain specified weights, when swept along at various velocities by moving water.

Table V.-Kinetic Energy of Moving Stones in Water. ${ }^{2}$

\begin{tabular}{|c|c|c|c|c|c|c|c|}
\hline \multicolumn{3}{|c|}{$\begin{array}{l}\text { Weight of stone } \\
\text { in air. }\end{array}$} & \multirow{2}{*}{$\begin{array}{l}\text { Specific } \\
\text { gravity of } \\
\text { stone. }\end{array}$} & \multicolumn{2}{|c|}{ Velocity. } & \multicolumn{2}{|c|}{ Kinetic energy. } \\
\hline $\begin{array}{c}\text { Kilo- } \\
\text { grammes. }\end{array}$ & lbs & ozs. & & $\begin{array}{l}\text { Metres per } \\
\text { second. }\end{array}$ & $\begin{array}{l}\text { Miles per } \\
\text { hour. }\end{array}$ & Watts. & $\begin{array}{l}\text { Foot- } \\
\text { poundals. }\end{array}$ \\
\hline $1 \cdot 5$ & 3 & $4 \cdot 8$ & $2 \cdot 3$ & 0.5 & 1 & $0 \cdot 106$ & $2 \cdot 52$ \\
\hline ” & " & ” & ” & $1 \cdot 0$ & $2 \frac{1}{4}$ & $0 \cdot 425$ & $10 \cdot 1$ \\
\hline$"$ & " & $"$ & $"$ & $2 \cdot 5$ & $5 \frac{1}{2}$ & $2 \cdot 65$ & 63 \\
\hline $0 \cdot 1$ & 0 & $3 \cdot 55$ & " & $5 \cdot 0$ & 11 & $0 \cdot 708$ & $16 \cdot 8$ \\
\hline $1 \cdot 5$ & 3 & $4 \cdot 8$ & 川 & 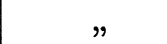 & , & $10 \cdot 6$ & 251 \\
\hline $4 \cdot 0$ & & $13 \cdot 2$ & " & " & ” & $28 \cdot 3$ & 673 \\
\hline $1 \cdot 5$ & 3 & $4 \cdot 8$ & 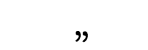 & $9 \cdot 0$ & 20 & $34 \cdot 35$ & 815 \\
\hline " & $"$ & ” & " & $15 \cdot 0$ & 34 & $95 \cdot 5$ & 2263 \\
\hline
\end{tabular}

1 J. Reid Moir, "The Striation of Flint Surfaces," Man, 1914 (90).

${ }^{2}$ I am indebted to Dr. J. W. Evans for some assistance in the consideration of this problem. 
Twice the weight of stone gives double the kinetic energy, while other weights follow in similar proportion. Differences in specific gravity would also make proportionate differences in the result. With regard to rivers, it may be remarked that the average velocity of a slow river is from one to three miles per hour, while the average velocity of a torrent may reach twenty miles per hour. We are not, however, concerned with the average velocity of the current, but with the velocity at which stones would be swept along for short distances in eddies, rapids, and the like.

I have little information on this point, but it is well to remember that the carrying power of currents varies as the sixth power of the increase of velocity; that is to say, three times the velocity generates 729 times the carrying power. With regard to the sea, it may be noted that during storms pebbles hurled up by the waves will sometimes break the windows of lighthouses at heights of about 100 metres above the sea. In order that a body might reach such a height, in a vertical course, it would have to be projected upwards at a velocity of a little over 44 metres per second. Such a high velocity as this would be exceptional even in the operation of marine waves: I do not suggest that it would ever be equalled in ordinary river work.

It is not such exceptionally violent forces which are the most important. As we have already seen, it is the more moderate forces which best induce selective chipping along the planes of least 'resistance. Generally speaking, it is such selective chipping under mechanical force which tends to simulate the guidance of intelligent design, rather than the more promiscuous effects of violent forces.

With regard to sub-soil pressure, I have obtained a number of weights of different soils, some of which have been kindly furnished for me by Mr. F. Sadler, the district surveyor of Acton, and others I have weighed myself. From the average of these I have calculated the pressure which falls upon stones according to their area and to their depth beneath the surface. Dry sand is the lightest, being 10 per cent. lower, while heavy ballast and sand is 10 per cent. higher, than the values given in the table. The last columns show the additional pressures due to various thicknesses of overlying snow or ice, which would have to be added to the other pressures given. All these pressures are calculated from surface density, and are consequently below the actual pressures that would be attained.

In this table the pressures are given in kilogrammes : to convert into pounds, multiply by 2 and add 10 per cent. to the product.

Turning back to Table III, it will be noted that the chain of open circles (the Kentish eoliths) are placed along the line of the " estimated favourable result," so that the pressure which would be needed to produce a similar depth of chipping under experimental conditions is indicated. It would be imprudent to push the analogy too far, as experimental conditions must differ from natural conditions. Even if the conditions were strictly comparable, it would not be possible to apply the necessary pressure shown in Table III to the depth in the sub-soil at which 
such pressure is exerted upon a flint of a given size, shown in Table VI. In some cases the pressure received by a flint would be distributed over its area, so that only a small fraction would be available as effective working pressure on the edge.

Table VI.-Sub-Soll Pressures upon Stones at Various Depths.

\begin{tabular}{|c|c|c|c|c|c|c|c|c|c|}
\hline \multicolumn{2}{|c|}{ Size of stone. } & \multicolumn{5}{|c|}{$\begin{array}{l}\text { Pressure in kilogrammes corresponding to } \\
\text { depth in metres or feet. }\end{array}$} & \multicolumn{3}{|c|}{ Add for covering of } \\
\hline $\begin{array}{l}\text { Square } \\
\text { centi- } \\
\text { metres. }\end{array}$ & $\begin{array}{l}\text { Square } \\
\text { inches. }\end{array}$ & $\begin{array}{c}0.305 \mathrm{~m} . \\
\text { or } \\
1.0 \mathrm{ft} .\end{array}$ & $\begin{array}{c}1.0 \mathrm{~m} . \\
\text { or } \\
3 \cdot 28 \mathrm{ft} \text {. }\end{array}$ & $\begin{array}{l}3 \cdot 0 \mathrm{~m} . \\
\text { or } \\
9 \cdot 84 \mathrm{ft} .\end{array}$ & $\begin{array}{c}6.1 \mathrm{~m} . \\
\text { or } \\
20 \cdot 0 \mathrm{ft} .\end{array}$ & $\begin{array}{c}20 \cdot 0 \mathrm{~m} . \\
\text { or } \\
65 \cdot 6 \mathrm{ft} .\end{array}$ & $\begin{array}{c}\text { Snow. } \\
3.05 \mathrm{~m} . \\
\text { or } \\
10^{\circ} 0 \mathrm{ft} .\end{array}$ & $\begin{array}{c}\text { Ice. } \\
30.5 \mathrm{~m} \text {. } \\
\text { or } \\
100 \mathrm{ft} .\end{array}$ & $\begin{array}{c}1 \mathrm{ce} . \\
100 \mathrm{~m} . \\
\text { or } \\
328 \mathrm{ft} .\end{array}$ \\
\hline $32 \cdot 3$ & 5 & $1 \cdot 87$ & $6 \cdot 13$ & $18 \cdot 4$ & $37 \cdot 5$ & $122 \cdot 6$ & $0 \cdot 8$ & $92 \cdot 5$ & $303 \cdot 5$ \\
\hline 60 & $9 \cdot 3$ & $3 \cdot 48$ & $11 \cdot 4$ & $34 \cdot 3$ & $69 \cdot 5$ & 228 & $1 \cdot 5$ & 172 & 565 \\
\hline 200 & 31 & $11 \cdot 6$ & 38 & 114 & 232 & 762 & 5 & 574 & 1882 \\
\hline 500 & $77 \cdot 5$ & 29 & .95 & 285 & 579 & 1902 & $12 \cdot 6$ & 1435 & 4705 \\
\hline 929 & $(=144$ sq.ft. $)$ & $53 \cdot 8$ & 176 & 530 & 1077 & 3536 & $23 \cdot 5$ & 2665 & 8743 \\
\hline
\end{tabular}

In other cases-and not infrequently-a number of stones would become wedged together during the process of solifluction, in such a manner that a great part of the pressure received upon the whole would be concentrated upon one; a large working force would thus be brought into action.

Prehistorians who have discussed these problems have been apt to overlook the importance of the difference between the inertness of the still condition, that is, the static force in equilibrium, and the dynamic forces which come into play so soon as differential movement is set up within the mass of a geological deposit.

The bulb of percussion.-Tables VII to X represent graphically the technical characters of the flakes or chips produced by different methods. These characters are shown as percentages of the total results taken as they chanced to come, and are classified under the following headings, which constitute the vertical abscissæ :-

F.E.-Nearly "flat" chips (that is without bulb) with éraillure, the latter being sometimes excessive.

B.E.-With poorly-developed bulb and éraillure.

F.-Nearly flat chips, without any bulb.

B.-With poorly-developed bulb.

B.B.-With well-developed plain bulb.

B.B.E.-With well-developed bulb and éraillure : this is the ideal, but not the exclusive, character of human flaking.

C.-With excessively strong conical bulb.

C.E.-As C, but with éraillure. 

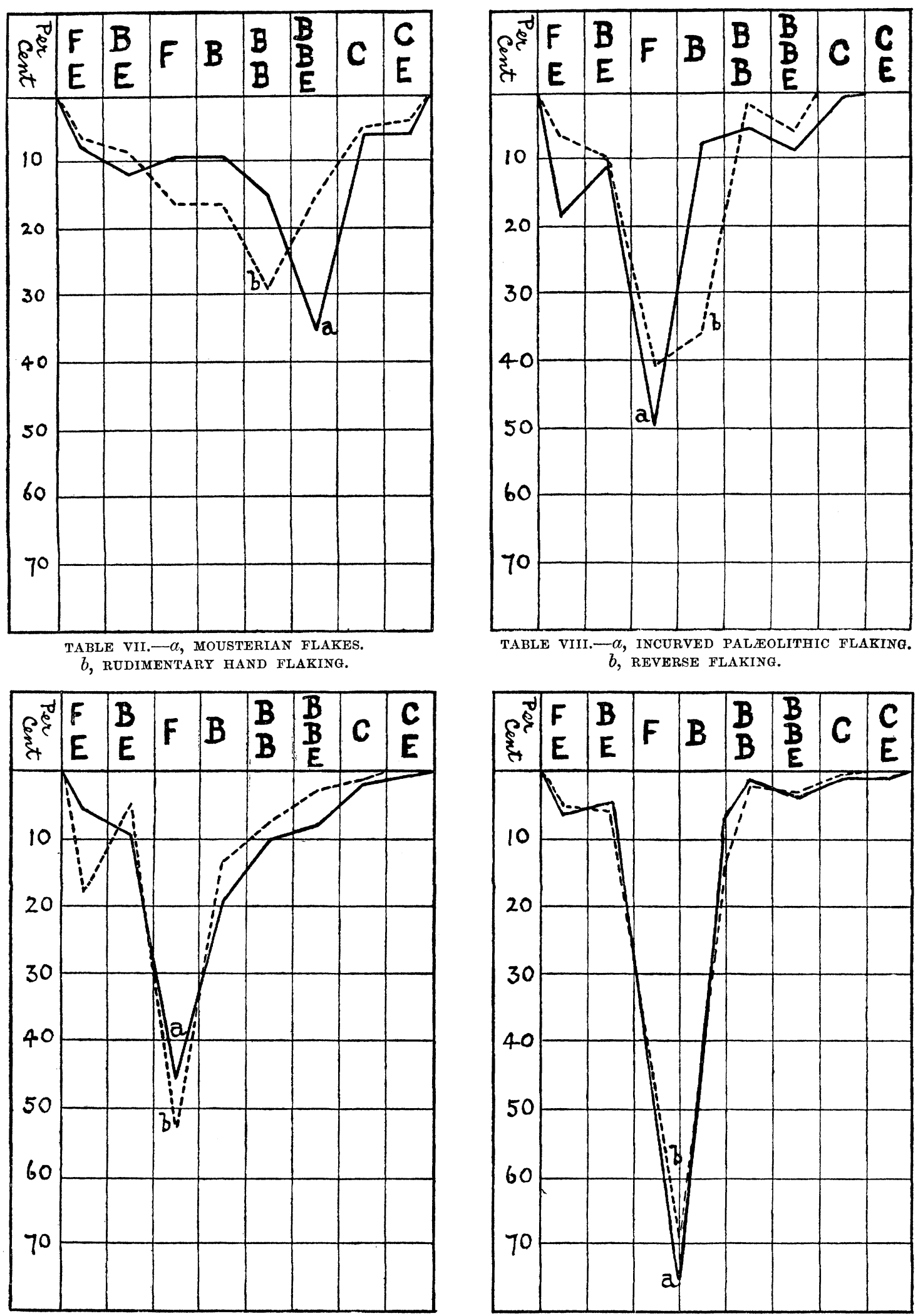

TABLE X.- $a$, "DEAD" CRUSHING.

$b$, ReVERSE CONCUSSIONS.

$b$, THE SLED FFFECTS.

Comparative Characters of the "Bulb of Percussion." 
It must be noted that all the chips coming into the B.B.E. column would pass as human flakes if found upon a prehistoric working floor.

The number of specimens and other details on which the percentages are based are as follows:-

Table VII. (a) 274 Mousterian flakes from the Stoke Newington palæolithic floor. (b) 195 flakes made from drift flint by myself by the most primitive method of striking the flint held in the left hand by a quartzite pebble held in the right hand, without regard to the form produced.

Table VIII. (a) 310 flakes from a palæolithic working site, which as a whole definitely belong to the incurved group, to which only 17 of the Stoke Newington flakes shown on the former table can be referred. Incurved flakes show a high degree of skill, and yet they controvert the conventional idea of the technical characters of an ideal human flake. (b) 141 flakes made by myself from drift flint by reverse flaking. These are all very rough chips and show no resemblance to the incurved flakes in their form. It doubtless requires a special knack, which I have been unsuccessful in mastering, to obtain a good result by reverse flaking.

Table IX. (a) 239 chips made by mechanical direct concussions. These show a much larger percentage coming into the B.B.E. column than the next group. (b) 147 chips made by mechanical reverse concussions. These effects show a resemblance to the incurved flakes, in the comparatively large percentage coming into the F.E. line.

Table X. (a) 83 pressure chips by dead crushing associated with a minimum of differential movement, from the base of the Tertiary formations at Harefield and other situations where these conditions are satisfied. (b) 369 chips made by the sled experiments of movement under pressure. These groups of pressure chips are difficult to classify under the same headings as others. The predominant tendency of pressure chips is to show a broad swelling without the clear-cut outline of a cone springing from a point of impact. I endeavoured to make the best classification that I could, and then plotted the percentage points in a different way from that adopted in the other cases in order to suggest the difficulty.

In general summary of these technical characters it must not be forgotten that they are here judged irrespective of the form of the flake as a whole. Viewed broadly, there can be no doubt that there are well-defined characters which are dominant in flaking or chipping by different methods. Still there is nothing absolute about these characters, and there is always a certain percentage produced by any method, which might well be mistaken for the product of a totally different method. Whatever one finds to be general or usual one also finds to be occasionally violated by an exceptional combination of adventitious conditions.

Associated with flatness of the flake or chip, there is a corresponding shallowness in the facet left by the removal of the flake. This, within similar limitations to those which are apparent in the percentages plotted on the tables, is often a very useful character. 
Rippling.-The rippling of the fractured surfaces is sometimes a rather elusive character to determine, but it may have some value in the case of " dead crushing." From material at present at my disposal it would appear that only about 11 per cent. of the chips by this method show ripplings of any strength, while the greater number of the chips show an unusual absence of any sign of rippling. With movement under pressure I think that there is less rippling than with concussions, but there is certainly much more than with dead crushing. The strongly rippled surfaces seem to approximate to 50 per cent. in most other methods, although there may be rather more rippling in the case of "reverse chipping" and "reverse flaking" than in the "direct" method. The characters of flakes and chips are illustrated in Plate XXXIX, Figs. 4 to 7.

Inner chipping angles.-I have plotted a series of observations of these upon squared paper and find that in the most primitive style of flaking in the hand, and also in most mechanical methods, the chief concentration is from 60 to 65 degrees. From this point, the curve drops more rapidly to 40 degrees and less rapidly on the other side to 90 degrees, with occasional records beyond these points upon either side.

Thus in the flaking or chipping angle, I have been unable to find any difference between the most primitive style of hand flaking and mechanical concussions. Ordinary rough human flaking, such as that of the Mousterian working-floor at Stoke Newington, shows the chief concentration at about 70 degrees, with but few below 50 or above 90 degrees. More advanced styles of human work may reach an average of 87 degrees, with a considerable number exceeding 90 degrees. $^{1}$ On the other hand, mechanical pressure also gives high angles of chipping, except where the pressure employed is in excess of that needed to do the work; in the latter event the angles tend to be lower.

Although the evidence of the angles, taken by itself, is thus full of contradictions, there is a point of comparison between the angles in the edge-chipping produced by mechanical movement under pressure, and the angles of the Kentish eoliths, which may be significant. Reference to the previous diagram (Fig. 9) will show that the inner chipping angles in the sled effects fall into three stages: $(a)$ the earlier chips that strike back the farthest, $(b)$ the middle chips, and $(c)$ the final blunting of the edge. I have added together a series of measurements of these angles, in the two cases, and averaged the products, with the following result :-

${ }_{1}^{1}$ High angles are not essential to the making of good flakes. Much of the modern Brandon work is executed at about $75^{\circ}$, while some is below $70^{\circ}$. It will be understood that in the making of core-implements the reverse generally holds, that is, the lower the angle the better the work. 
Table XI.-Comparison of Chipping ANgles.

\begin{tabular}{|c|c|c|c|c|c|c|c|}
\hline \multirow{2}{*}{\multicolumn{4}{|c|}{ Stages of edge-chipping. }} & \multicolumn{2}{|c|}{ Experimental sled effects. } & \multicolumn{2}{|c|}{$\begin{array}{c}\text { Kentish eoliths } \\
\text { (Prestwich collection). }\end{array}$} \\
\hline & & & & $\begin{array}{c}\text { Number of } \\
\text { measurable } \\
\text { examples. }\end{array}$ & $\begin{array}{l}\text { Average } \\
\text { angle in } \\
\text { degrees. }\end{array}$ & $\begin{array}{c}\text { Number of } \\
\text { measurable } \\
\text { examples. }\end{array}$ & $\begin{array}{l}\text { Average } \\
\text { angle in } \\
\text { degrees. }\end{array}$ \\
\hline First & $\ldots$ & ... & $\ldots$ & 42 & $55 \cdot 45$ & 37 & $56 \cdot 1$ \\
\hline Second & $\ldots$ & $\ldots$ & $\ldots$ & 38 & $76 \cdot 5$ & 29 & $83 \cdot 3$ \\
\hline Third & $\ldots$ & $\ldots$ & $\ldots$ & 35 & $106 \cdot 74$ & 37 & $114 \cdot 4$ \\
\hline
\end{tabular}

The slight differences to be noted between the above two series are instructive. In the sled effects a smaller proportion show the final blunting, and, in addition, this final blunting is less obtuse than in the case of the eoliths. These features point to the conclusion that the eoliths, as compared with the sled effects, have been subjected to the more prolonged operation of a minimum force. As we have seen, excess of pressure tends to give lower angles of chipping. ${ }^{1}$

It appears to me that the comparison of the chipping angles confirmis the conclusion reached from the comparison of the forms, namely, that the Kentish eoliths are due to the operation of mechanical movement under pressure.

\section{Conclusions.}

In the investigations detailed in the foregoing paper, I have not confined attention to those points which bear directly, or even indirectly, upon the problem of the eoliths, but I have aimed at dealing with the elementary conditions of flint chipping on general lines. But as the controversy which turns upon the problem of the eoliths is a burning one at the present time, I will set down the conclusions at which I have arrived in this matter as clearly and concisely as possible.

(1) That the application of mechanical force, particularly of differential movement under pressure, acting upon flints of suitable shape, produces edge-chipping which has the same characteristics as that of the eoliths.

(2) That the amount of pressure required to effect the chipping observed upon eoliths of Kentian type is found within the limits of superficial drift deposits, if the static force in equilibrium should become a dynamic force through movement taking place.

1 It may be noticed that there is an apparent contradiction between this statement and that previously made in Section 5, that, other things being equal, a low angle chip requires less force than a high angle chip. The explanation lies in the fact that under the special conditions dealt with here, the low angle chip has of necessity such a much larger area than the high angle chip that the influence of the angle is counterbalanced. 
Journal of the Royal Anthropological Institute, Vol. XLIV, 1914, Plate XXXVIII.

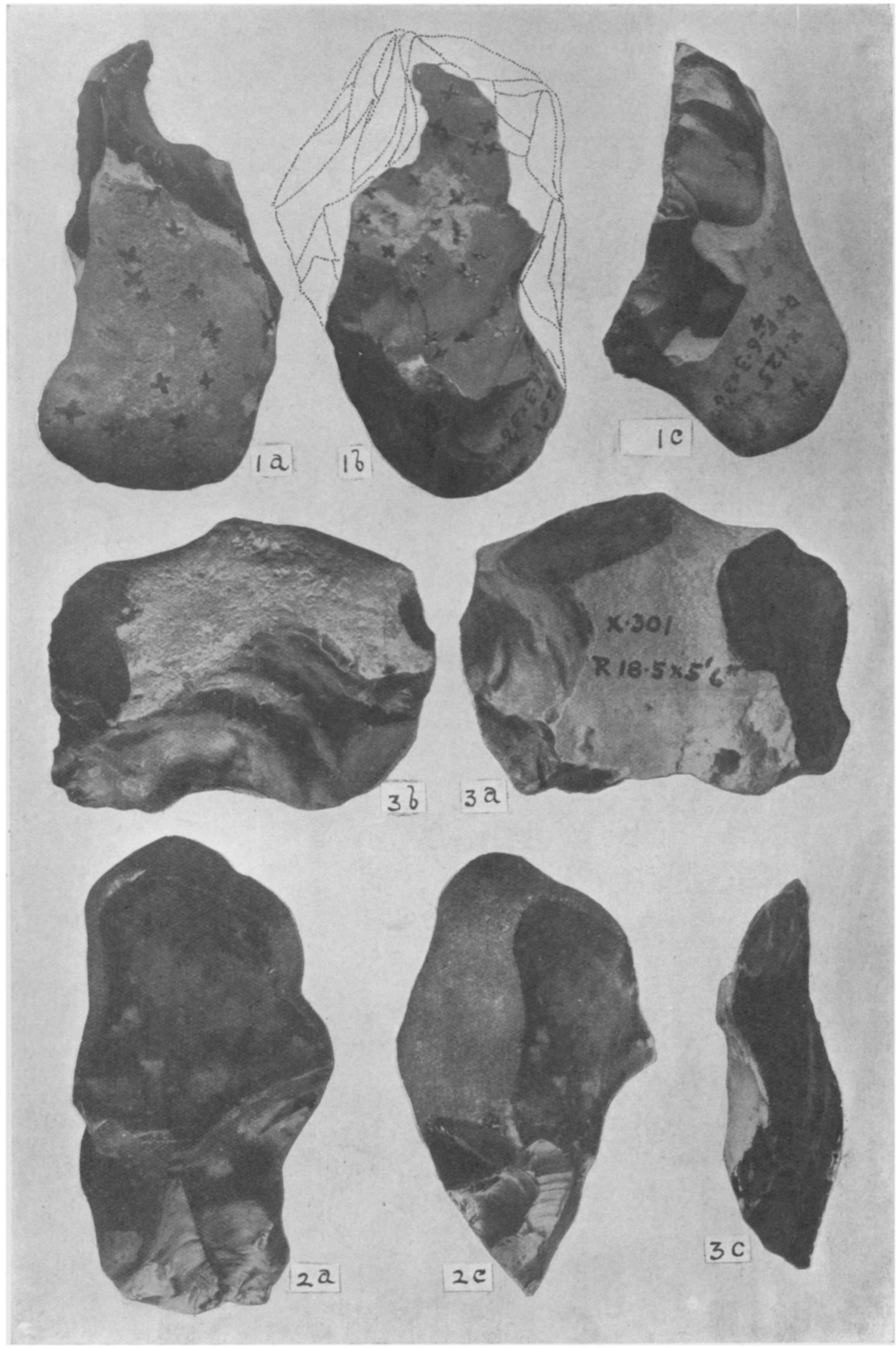


Journal of the Royal Anthropological Institute, Vol. XLIV, 1914, Plate XXXIX.

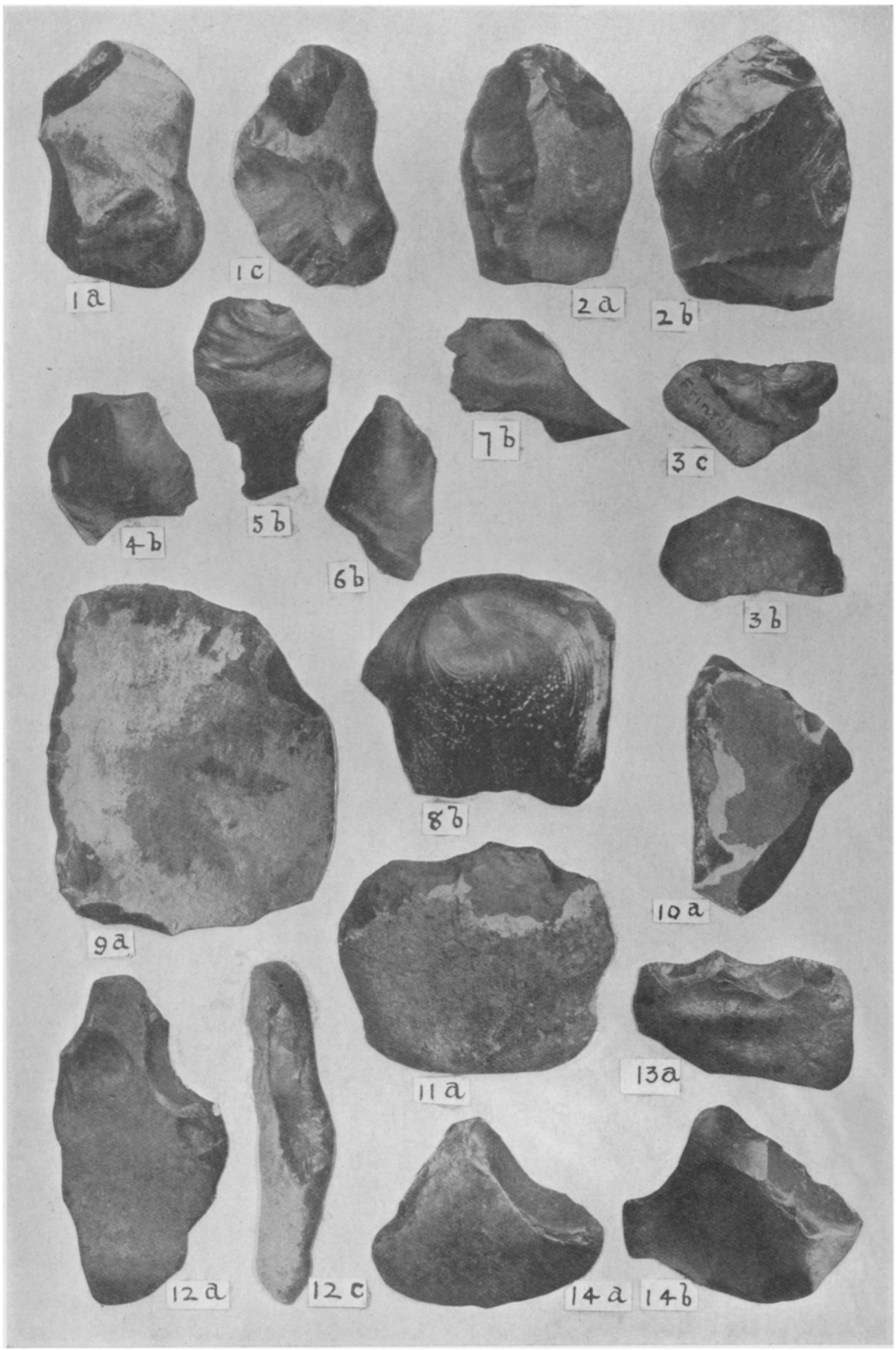

EXPERIMENTAL AND OTHER FLINT CHIPPING.

S.H.W. Photo. 


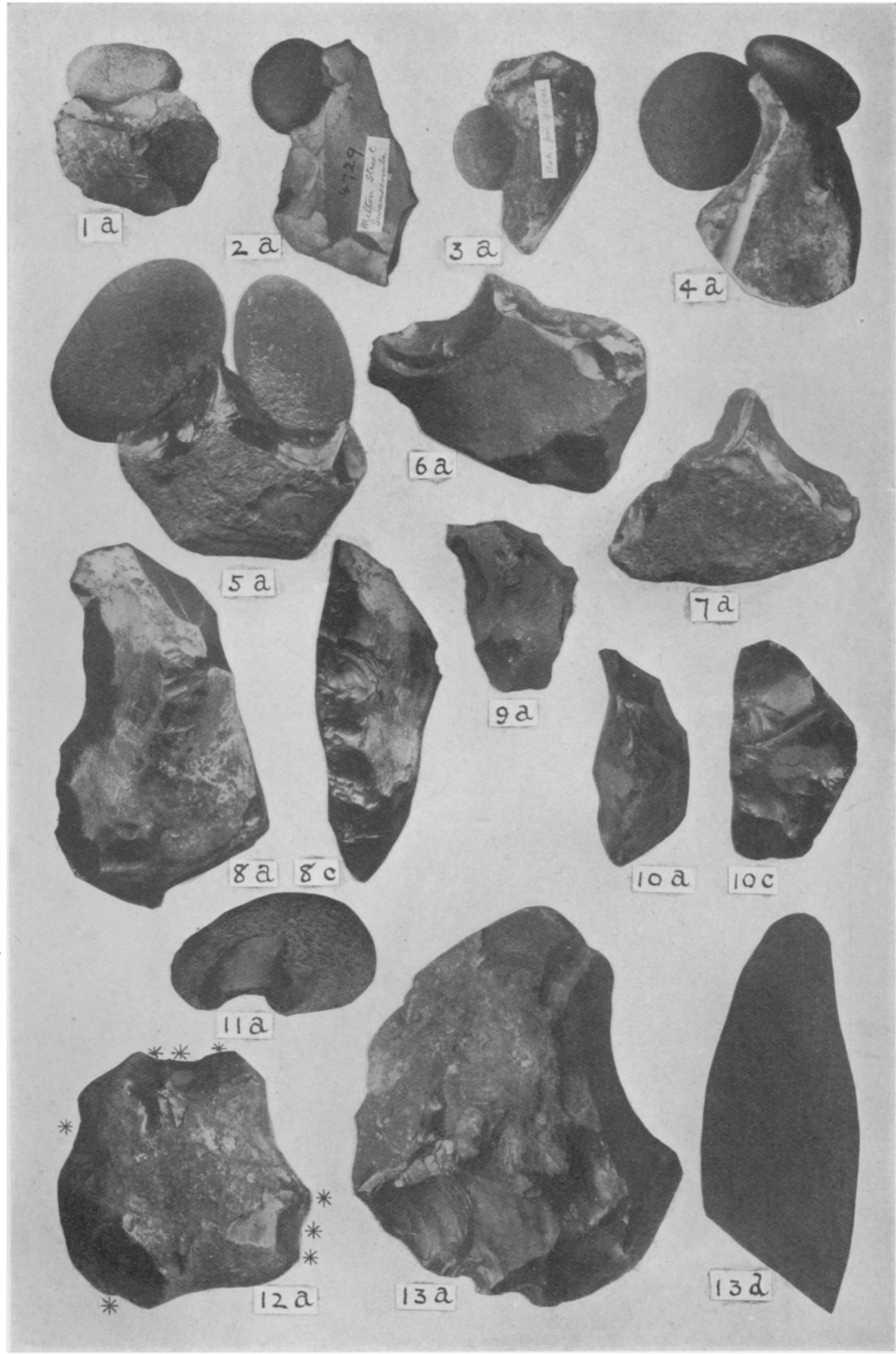

EXPERIMENTAL AND OTHER FLINT CHIPPING.

S.H.W. Photo. 
(3) That the striated surfaces associated in the field with eolithic chipping indicate that the flints have been subjected to those differential movements under pressure which experiment proves to be capable of effecting the chipping.

(4) That the larger chipping of the sub-crag flints has not been reproduced by experimental methods, because differential movements under adequate pressure have not yet been employed in flint experiments.

(5) That as a matter of personal judgment, based upon more than twenty years of specialized research, it is my opinion that the chipping upon the sub-crag flints presents non-human characteristics, and follows the same general lines that are observed upon a smaller scale in the operation of small forces.

(6) That the powerful striations associated with the sub-crag flints are suggestive of equally powerful forces having operated upon them, which it is reasonable to suppose (arguing from the known lesser to the unknown greater) would also be capable of effecting the chipping.

(7) That extensive flint-chipping is found in the early Tertiary formations under circumstances which preclude the possibility of the intervention of man, and proving the chipping to have been produced in situ by sub-soil pressure.

(8) That the best and most characteristic of the eoliths present features which point to pressure as their cause; but that with these are many which were probably caused by the accidental concussion of one stone against another in the course of natural erosion, which, acting along the planes of least resistance of the flint, frequently produces a deceptive simulation of deliberate workmanship.

In conclusion, let me say that I have no prejudice against the existence of man in the Pliocene period: it is simply a question of obtaining the facts to prove his existence at that time. But in view of the evidences detailed above it appears to me imprudent-indeed, to my mind, I would say practically impossible-to accept these chipped flints as throwing light upon that early chapter of human, or immediately pre-human, history, which I, no less than the most enthusiastic of my opponents, should like to see opened up before us as clearly as the Palæolithic Age now stands revealed.

\section{DESCRIPTION OF THE PLATES.}

The scale is not quite uniform, but is approximately half natural size, or rather less. The letters against the numbers of the figures have the following significance: $a$, the convex side of the specimen; $b$, the basal plane, or the flatter side, or the inner face of flakes and chips ; $c$, the edge view ; $d$, the section.

\section{Plate XXXVIII.}

Fig. 1.-See page 420 .

Fig. 2.- See page 422 .

Fig. 3. - See page 422 .

VOL. XLIV. 


\section{Plate XXXIX.}

Fig. 1.-See page 421.

Fig. 2.-See page 421 .

Fig. 3.-Wave action upon a modern sea beach; selective $\boldsymbol{a}$ chipping shown in the side view (c), the basal plane (b) being unchipped.

Fig. 4.-Ideal human flake, showing sharply defined conical bulb, partly cut away on one side by the éraillure.

Fig. 5.--Incurved flake, showing absence of bulb and strong ripplings.

Fig. 6.-Ideal chip by mechanical reverse chipping. The ideal chip by direct chipping is intermediate in character, between Figs. 4 and 6 .

Fig. 7.--Ideal chip by pressure. The bulb is a broad swelling, and there is no rippling.

NoTE.--None of the above characters of flakes and chips are constant, but they represent marked tendencies.

Fig. 8.-Ideal frost scale. The ripplings are roughly concentric to a fragment of fossil.

Fig. 9.-Sled crushing. High-angle edge-chipping, assuming a pseudo-Mousterian form. Brandon flint. All the other examples of experimental crushing are made from drift flint.

Fig. 10.- Sled crushing. Straight-edged form.

Fig. 11.- Sled crushing. Edge-chipping with incipient notches.

Fig. 12.-Sled crushing. Single notch. This is one of the most frequent forms produced.

Fig. 13.-Sled crushing. Double notch, or incipient point.

Fig. 14.-Cart-wheel crushing. Point with reverse chipping on either side. This illustrates the production of this form by the fortuitous application of pressure.

\section{Plate XL.}

Fig. 1.-Striated Palæolithic flake from the Kent Plateau, with eolithic notch made subsequently to its patination. It is photographed against a pebble to illustrate the theory of the production of the notch by pressure against another stone.

Fig. 2.-Palæolithic trimmed flake from Swanscombe, with eolithic notch made subsequently to its patination, similarly photographed.

Fig. 3.-Eolith from the pit of 1902 at Ash, on the Kentish Plateau, photographed in the same manner as Figs. 1 and 2.

Fig. 4.-Crushing. Unsymmetrical point, made by pressure against the stones of a gravel path.

Fig. 5.-Crushing in the same manner as Fig. 4.

Fig. 6.-Crushing. Unsymmetrical short point.

Fig. 7.-Crushing. Point.

Fig. 8.-Sled crushing. This shows a marked approach towards the rostro-carinate form.

Eig. 9.-Cart-wheel crushing. Small rostro-carinate.

Fig. 10.-Cart-wheel crushing. Small but very perfect rostro-carinate. The a chipping in this specimen has cut so far back into the stone at a high angle, that chipping in the $\delta$ direction has taken place from the carina.

NoтE.-Figs. 4 to 10 illustrate the close association of the double-notches-with-point and the rostro-carinate form. They differ only in relative proportions : the essential conditions of the chipping are the same.

Figs. 11-13.-Dead crushing from the Reading Beds at Harefield. Fig. 11 shows a notch squeezed out in one piece by excess of pressure. Fig. 12 shows edge-chipping at the points of contact with the stones on which it rested. The position of the chips is indicated by stars, one part having a shallow notch with three chips. Fig. 13 is a. pseudo-hand-axe : the admirable bevel of the cutting edge is shown in the section. 